\title{
Developmental and Adult GAP-43 Deficiency in Mice Dynamically Alters Hippocampal Neurogenesis and Mossy Fiber Volume
}

\author{
Sarah E. Latchney ${ }^{a} \quad$ Irene Masiulis ${ }^{a} \quad$ Kimberly J. Zaccariac ${ }^{c}$ Diane C. Lagace ${ }^{a}$ \\ Craig M. Powella,b James S. McCasland ${ }^{c}$ Amelia J. Eisch $^{a}$ \\ Departments of a sychiatry and ${ }^{b}$ Neurology and Neurotherapeutics, University of Texas Southwestern Medical \\ Center, Dallas, Tex., and ' Department of Cell and Developmental Biology, SUNY Upstate Medical University, \\ Syracuse, N.Y., USA
}

\section{Key Words}

Hippocampus · Dentate gyrus · Granule cell layer .

Subgranular zone $\cdot$ Mossy fibers $\cdot$ Ki67 cells .

Phosphorylated histone H3 - Doublecortin .

Synaptoporin · Proliferation

\begin{abstract}
Growth-associated protein-43 (GAP-43) is a presynaptic protein that plays key roles in axonal growth and guidance and in modulating synapse formation. Previous work has demonstrated that mice lacking one allele of this gene (GAP$43+/-$ mice) exhibit hippocampal structural abnormalities, impaired spatial learning and stress-induced behavioral withdrawal and anxiety, behaviors that are dependent on proper hippocampal circuitry and function. Given the correlation between hippocampal function, synaptic connectivity and neurogenesis, we tested if behaviorally naïve GAP43+/- mice had alterations in either neurogenesis or synaptic connectivity in the hippocampus during early postnatal development and young adulthood, and following behavior testing in older adults. To test our hypothesis, we examined hippocampal cell proliferation (Ki67), number of immature neuroblasts (doublecortin, DCX) and mossy fiber volume (synaptoporin) in behaviorally naïve postnatal day 9 (P9)
\end{abstract}

and P26, and behaviorally experienced 5- to 7-month-old GAP-43+/- and +/+ littermate mice. P9 GAP-43+/- mice had fewer Ki67+ and DCX+ cells compared to +/+ mice, particularly in the posterior dentate gyrus, and smaller mossy fiber volume in the same region. In young adulthood, however, male GAP-43+/- mice had more Ki67+ and DCX+ cells and greater mossy fiber volume in the posterior dentate gyrus relative to male $+/+$ mice. These increases were not seen in females. In 5- to 7-month-old GAP-43+/- mice (whose behaviors were the focus of our prior publication), there was no global change in the number of proliferating or immature neurons relative to $+/+$ mice. However, more detailed analysis revealed fewer proliferative DCX + cells in the anterior dentate gyrus of male GAP-43+/- mice compared to male $+/+$ mice. This reduction was not observed in females. These results suggest that young GAP-43+/- mice have decreased hippocampal neurogenesis and synaptic connectivity, but slightly older mice have greater hippocampal neurogenesis and synaptic connectivity. In conjunction with our previous study, these findings suggest that GAP-43 is dynamically involved in early postnatal and adult hippocampal neurogenesis and synaptic connectivity, possibly contributing to the GAP-43+/- behavioral phenotype.

(c) 2014 S. Karger AG, Basel

\section{KARGER}

E-Mail karger@karger.com

www.karger.com/dne
(C) 2014 S. Karger AG, Basel

0378-5866/14/0361-0044\$39.50/0
Amelia J. Eisch

Department of Psychiatry

5323 Harry Hines Blvd

Dallas, TX 75390 (USA)

E-Mail amelia.eisch@utsouthwestern.edu 


\section{Introduction}

Synapse connectivity of neural circuits is critical for proper structural organization between and within brain regions, and enables many neurological functions including cytoskeletal dynamics, neurotransmission, sensory processing, and cognition [1]. Variations in genes and proteins that control synapse development and refinement are evident in humans afflicted with neuropsychiatric conditions that are marked by anxiety, deficits in communication and social interaction, and sensory and cognitive impairments $[1,2]$. Diminished synaptic plasticity is also evident in animal models of neuropsychiatric disorders [1-4]. Given the essential role for synaptic proteins in neuronal plasticity and disease pathology, there is interest in investigating how deficits in synaptic proteins impact the development and remodeling of neural circuits.

Growth-associated protein-43 (GAP-43) is a presynaptic protein located on the growth cones of axons, and it plays key roles in cytoskeletal dynamics like axonal growth and guidance and synapse formation [5, 6]. Mice harboring GAP-43 genetic variants exhibit early brain overgrowth and irregular axonal sprouting and synaptogenesis that are proposed to contribute to the behavioral deficits in GAP-43 mutants [7-13] such as altered hippocampal-dependent function [14-16]. For example, mice heterozygous for GAP-43 (GAP-43+/-) display increased vulnerability to stress and resistance to change in hippocampal-dependent tasks [17]. This suggests a critical role for GAP-43 in hippocampal synaptic homoeostasis and neural processing.

One aspect of hippocampal neuroplasticity that has not been explored in GAP-43 mutants is neurogenesis. In mice, hippocampal neurogenesis peaks right after birth, and then continues at a lower rate throughout adulthood [18-21]. In the early postnatal period, rapidly dividing neural progenitors are evident in the granule cell layer (GCL) of the hippocampal dentate gyrus. With aging, the progenitors become progressively restricted to the inner border of the GCL, or subgranular zone (SGZ) [18]. Those postnatal-born progenitors that survive develop into neurons [18] and extend their axons to the CA3 hippocampal region via the mossy fiber bundle [22-24]. A functional role for postnatal- and adult-born neurons is increasingly evident, as their depletion results in spatial learning and memory deficits and other behavioral disturbances $[25,26]$. Disruption in synaptic transmission between the dentate gyrus and CA 3 also impairs memory [27]. Moreover, susceptibility to stress (as seen in GAP-
$43+/-$ mice) is associated with long-term changes in hippocampal neurogenesis $[28,29]$, and hippocampal neurogenesis in turn is critical for regulating response to stress [29-31].

Given the correlation between hippocampal function, neurogenesis and synaptogenesis [32, 33], we hypothesize that the behavioral phenotype observed in GAP-43+/- mice [17] is associated with decreased neurogenesis and altered synaptic connectivity within the hippocampus. To test this, we examined neurogenesis and mossy fiber volume during early postnatal development and young adulthood, and following behavior testing in adult GAP-43+/- and $+/+$ littermates. We found that young GAP-43+/- mice have regional deficits in hippocampal neurogenesis and synaptic connectivity, while young adult mice have increases in these metrics. Our correlative results - in combination with our previous study [17] - encourage future causative studies to test the link between impaired hippocampaldependent processing, abnormal hippocampal neurogenesis and reorganization of hippocampal mossy fiber axons.

\section{Materials and Methods}

Mice and Bromodeoxyuridine Administration

Mice were bred and maintained in accordance with $\mathrm{NIH}$ Guidelines for the Care and Use of Laboratory Animals. Experimental procedures were approved by the Institutional Animal Care and Use Committee at the University of Texas Southwestern (UTSW) Medical Center and the State University of New York Upstate Medical University (SUNY Upstate). GAP-43+/- mice were bred $[9,17]$ and wild-type littermates $(\mathrm{GAP}-43+/+)$ were controls. Three ages of GAP-43+/- and +/+ mice were used: postnatal day 9 (P9) behaviorally naïve mice, P26 behaviorally naïve mice, and 5- to 7-month-old behaviorally experienced mice whose behavioral data have been previously published [17]. The 5- to 7-month-old GAP-43+/- and +/+ littermates received bromodeoxyuridine (BrdU) $[28,34]$ and were sacrificed $2 \mathrm{~h}$ later (fig. 5a). P9 and P26 mice did not receive BrdU injections, but were examined for endogenous markers relevant to hippocampal neurogenesis.

Tissue Preparation and Immunohistochemistry

The 5- to 7-month-old mice were anesthetized and perfused as described previously $[35,36]$, while P9 and P26 mice were euthanized and brains were immersion-fixed in $4 \%$ paraformaldehyde at SUNY Upstate prior to being sent to UTSW. All brains were cryoprotected and sectioned for stereology $[35,36]$, with the exception that P9 coronal sections were collected at $40 \mu \mathrm{m}$ in a 1:6 series. Coded slide-mounted immunohistochemistry (IHC) and subsequent analysis was performed with antibodies against BrdU, doublecortin (DCX), Ki67, phosphorylated histone H3 (pHisH3), and synaptoporin as previously described [35-37]. To minimize 
variability and enable quantification of resulting stains, tissues from GAP-43+/- and +/+ mice to be compared were processed through IHC simultaneously.

Bright-Field Microscopic Analyses and Cell Quantification

Following IHC of hippocampal section, cell quantification was performed. Unbiased estimates for Ki67 and DCX+ cells in P9 mice and DCX+ cells in P26 mice were obtained using stereology on an Olympus BX51 System Microscope (Optronics, Goleta, Calif., USA). Cell counts were collected using the Optical Fractionator Probe within the Stereo Investigator software (MBF Bioscience, MicroBrightField, Inc., Williston, Vt., USA) [38, 39]. Counting was performed using a $100 \times / 1.4 \mathrm{NA}$ oil immersion lens for P9 and a $40 \times / 0.63 \mathrm{NA}$ lens for P26. The optical disector height was 12 $\mu \mathrm{m}$. The area-sampling fraction was $1 / 25$ and the section-sampling fraction was $1 / 6$ for P9 and $1 / 9$ for P26. Ki67+ cells in P26 mice and BrdU+ and DCX+ cells in the 5- to 7-month-old mice were visualized with an Olympus BX51 microscope using a 40×/0.63 NA lens with continuous adjustment through the depth of the section [37]. Exhaustive counts for BrdU+, Ki67+ and DCX+ cells in every 9th dentate gyrus section were collected using the optical fractionator method [28]. Because the raw counts (before multiplication) for + cells were low according to disector/fractionator standards [40], both the area- and height-sampling fractions were 1 $[28,41,42]$. For the 5- to 7-month-old mice, the number of BrdU+ cell clusters and the number of BrdU+ cells/cluster were also quantified [37]. For all metrics, the distribution of + cells in the dentate gyrus was also analyzed at different distances from the Bregma; data are presented as total number of cells in the SGZ at each septotemporal point.

\section{Dendrite Quantification of DCX+ Cells}

To assess maturation of DCX+ SGZ cells in 5- to 7-month-old mice, DCX+ cells were categorized into 3 categories based on dendritic morphology: proliferative, intermediate and postmitotic [43, 44]. Proliferative cells had no or a short dendritic process $(<10 \mu \mathrm{m}$; fig. $6 \mathrm{a}-\mathrm{c}$ ); intermediate cells had dendrites $>10 \mu \mathrm{m}$ long which did not reach into the molecular layer (fig. $6 \mathrm{~d}$ ), and postmitotic cells had dendritic processes that reached into the molecular layer (fig. 6e).

\section{Confocal Microscopy and Phenotypic Analyses}

Phenotypic analyses were performed using confocal microscopy with optical sectioning in the $\mathrm{Z}$ plane (Zeiss Axiovert 200/ LSM510-META; emission wavelengths 488, 543 and $633 \mathrm{~nm}$ ) as previously described [37]. Phenotyping was used to characterize the mitotic nature of Ki67+ cells in P9 mice (Ki67/pHisH3 IHC; fig. $1 \mathrm{~d}-\mathrm{f}$ ), and to confirm the proliferative versus postmitotic nature of DCX+ SGZ cells of 5- to 7-month-old mice (DCX/Ki67 IHC; fig. $6 \mathrm{n}-\mathrm{u})$. For P9 mice, the ratio of single-labeled $(\mathrm{Ki} 67+\mathrm{pHisH3}-)$ or double-labeled $(\mathrm{Ki67}+\mathrm{pHisH}+)$ cells in relation to the total number of $\mathrm{Ki} 67+$ was calculated for each mouse. For 5- to 7-month-old mice, the ratio of single-labeled $(\mathrm{DCX}+\mathrm{Ki} 67-)$ or double-labeled $(\mathrm{DCX}+\mathrm{Ki} 67+)$ cells in relation to the total number of DCX+ was calculated for each mouse. The resulting ratios from each phenotypic category were statistically analyzed and/or were multiplied by the absolute number of Ki67+ (P9 mice; fig. 1e, f) or DCX+ cells (5- to 7-month-old mice; fig. 6o, s) acquired from stereological quantification (described above) to obtain the total number of single- or double-labeled cells.
Volume Quantification of Hippocampal Mossy Fibers

Volume quantification of the synaptoporin+ mossy fiber tract was performed using the Cavalieri Probe within Stereo Investigator [45]. For P9 and 5- to 7-month-old mice, every 6th or 9th section, respectively, was examined via an Olympus BX51 microscope with a $10 \times /$ NA 0.30 lens to assess the size of the hilus, the suprapyramidal mossy fiber field (SMF) and the infrapyramidal mossy fiber field (IMF). Areas were determined using Stereo Investigator's area measurement tool. Volumes were determined by multiplying the sum of the areas by the sampling fraction and the section thickness ( $40 \mu \mathrm{m}$ for P9 and $30 \mu \mathrm{m}$ for 5 - to 7 -monthold mice). The Gunderson coefficient of variance for each brain was always $<10 \%$. Data are reported as the total estimated volume (in cubic micrometers) of the mossy fiber field/brain and as total volume of the respective mossy fiber field at each septotemporal point.

\section{Statistical Analyses and Data Presentation}

As shown in figure legends, data are expressed as mean \pm SEM from a minimum of 5 mice/genotype. Data from behaviorally naive P26 and behaviorally tested 5- to 7-month GAP-43+/- and +/+ mice were analyzed by sex, whereas male and female P9 brains were combined for analysis. Statistical analyses were performed with either unpaired t test or 2-way analysis of variance (ANOVA) where appropriate (GraphPad Prism 6.0). Sidak post hoc comparisons were used to analyze significant ANOVAs. $\mathrm{p}<0.05$ were considered statistically significant.

\section{Results}

\section{P9 GAP-43+/- Mice Have Fewer Proliferating Cells} and Immature Neurons in the GCL

We first examined GAP-43+/- and +/+ littermates at P9 (fig. 1a), an early postnatal time point when total and phosphorylated forms of GAP-43 peak [11]. This developmental age in mice also coincides with a critical period of axon elongation, terminal arborization and early synaptogenesis [46, 47], all processes in which GAP-43 has a putative role. Therefore, we hypothesized that P9 GAP$43+/-$ mice would have diminished indices of hippocampal neurogenesis compared to $+/+$ mice.

We first analyzed Ki67+ cells as an endogenous measure of cell proliferation [34]. The distribution of Ki67+ GCL cells at P9 was similar to published work [38], with Ki67+ cells evident throughout the entire GCL width (fig. 1b), signifying high proliferative activity in the P9 hippocampal dentate gyrus. Stereology revealed a $17 \%$ decrease in the total number of Ki67+ cells in P9 GAP$43+/-$ versus $+/+$ mice (fig. $1 \mathrm{c}, \mathrm{p}<0.05$ ). As the dentate gyrus differs in cellular composition and function along the GCL in the distance from the Bregma [48-53], we also examined Ki67+ cell number in the distance from the Bregma. There was a significant main effect of Breg- 


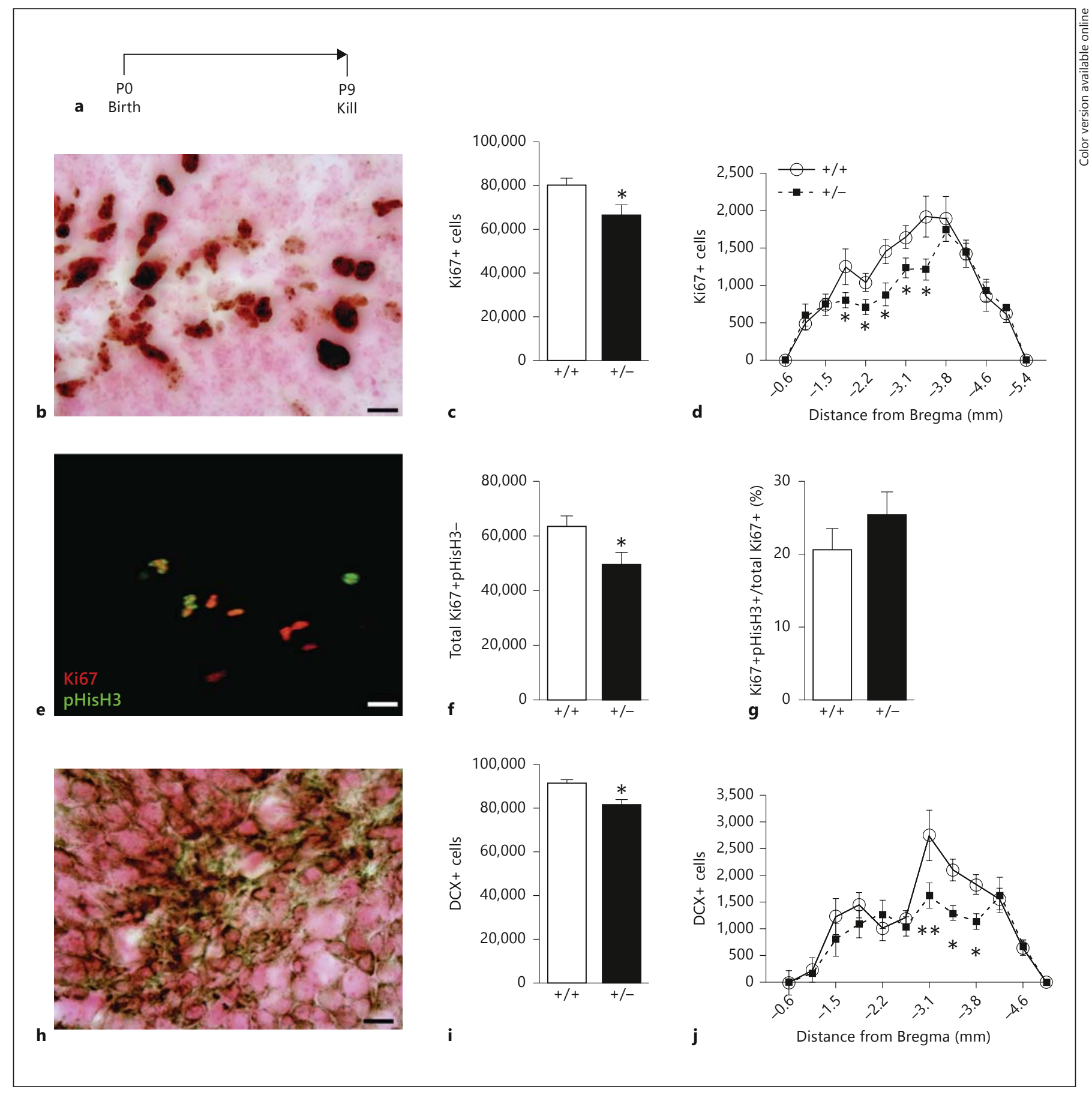

Fig. 1. P9 GAP-43+/- mice have reduced indices of hippocampal neurogenesis. a Experimental timeline. Behaviorally naïve GAP$43+/+$ and +/- mice were killed at P9. b Representative photomicrograph of dentate gyrus counterstained with Fast Red (pink) and immunostained with an antibody against Ki67 (brown). c, d Ki67+ cell number in GAP-43+/- vs. +/+ mice examined as total number of cells (c) and over the rostrocaudal axis of the dentate gyrus (d). e Representative merged 3D projection image of dentate gyrus immunostained with antibodies against $\mathrm{Ki} 67$ (red) and $\mathrm{pHisH} 3$ (green). f, $\mathbf{g}$ The number of single-labeled Ki67+pHisH3- (f) and the proportion of $\mathrm{Ki} 67+$ cells that are $\mathrm{pHisH} 3+(\mathbf{g})$ in GAP-43+/vs. +/+ mice. $\mathbf{h}$ Representative photomicrograph of dentate gyrus counterstained with Fast Red (pink) and immunostained with an antibody against DCX (brown). $\mathbf{i}, \mathbf{j}$ DCX+ cell number in GAP$43+/-$ vs. +/+ mice examined as total number of cells (i) and over the rostrocaudal axis of the dentate gyrus (j). Data expressed as means \pm SEM ( $n=5 /$ genotype). c, f, g, i Analyzed by Student's $t$ test. $\mathbf{d}, \mathbf{j}$ Analyzed by 2 -way ANOVA with Sidak post hoc test. ${ }^{*} \mathrm{p}<$ $0.05,{ }^{* *} \mathrm{p}<0.01$ vs. $+/+$. Scale bars: $\mathbf{b}, \mathbf{e}, \mathbf{h}=10 \mu \mathrm{m}$. 
$\mathrm{ma}\left(\mathrm{F}_{12,104}=29.23, \mathrm{p}<0.0001\right)$ and genotype $\left(\mathrm{F}_{1,104}=\right.$ 9.46, $\mathrm{p}=0.002)$, with a near-significant genotype $\times$ Bregma interaction $\left(\mathrm{F}_{12,104}=1.84, \mathrm{p}=0.05\right)$. Post hoc analysis revealed fewer Ki67+ cells in P9 GAP-43+/versus $+/+$ mice -1.8 to $-3.4 \mathrm{~mm}$ from the Bregma (fig. 1d). To assess whether the lower Ki67+ cell number was due to delayed/premature mitosis, we used 3D phenotypic analyses of sections stained for $\mathrm{Ki} 67$ and the endogenous G2/M cell cycle marker pHisH3 (fig. 1e-g) [37]. Ki67+ cells were, as expected, far greater in number than pHisH3 + cells, as Ki67 labels cells in all phases of the cell cycle except G2/M in vivo, while pHisH3 labels cells only in the late G2/M phase [37]. Almost all pHisH3+ cells were also Ki67+, but not all Ki67+ cells were pHisH3+ (fig. 1e). Each Ki67+ cell was categorized as single-labeled (Ki67+pHisH3-) or double-labeled (Ki67+pHisH3+; fig. 3e-g). Phenotypic analysis revealed a $22 \%$ reduction in Ki67+pHisH3 - cells in +/versus $+/+$ mice (fig. 1f, $\mathrm{p}<0.05$ ). This is consistent with figure 1c, verifying significantly fewer Ki67+ SGZ cells in $+/-$ mice. However, the proportion of Ki67+ cells that were $\mathrm{pHisH} 3+$ did not differ between $+/+$ and $+/-$ mice (fig. 1g, p > 0.05), suggesting that the reduced Ki67+ cell numbers in P9 GAP-43+/- mice could be likely due to an overall reduction in the number of proliferating cells or due to a shorter length of the entire cell cycle in $+/-$ mice. Together, these data suggest that GAP- $43+/-$ mice exhibit a significant decrease in the number of dividing progenitors.

DCX+ GCL cells were also quantified to assess immature neuroblasts $[38,39]$. The appearance and distribution of DCX + cells in +/+ P9 mice were similar to published work [38]: DCX+ cells lacked processes, were evident in the inner two thirds of the GCL, and were marked by immunostaining restricted to the outer soma (fig. 1h). Stereological quantification of total DCX + in the GCL of DCX + cells in $+/+$ versus $+/-$ mice revealed $12 \%$ fewer DCX + cells in P9 GAP-43+/- versus +/+ mice (fig. 1i, $\mathrm{p}<$ $0.05)$. When analyzed across Bregma, there was a significant main effect of Bregma $\left(\mathrm{F}_{11,96}=21.86, \mathrm{p}<0.0001\right)$ and genotype $\left(\mathrm{F}_{1,96}=9.84, \mathrm{p}<0.01\right)$, and a significant genotype $\times$ Bregma interaction $\left(\mathrm{F}_{11,96}=1.98, \mathrm{p}<0.05\right)$. Post

Fig. 2. P9 GAP-43+/- mice exhibit regional reductions in mossy fiber volume. a Representative low magnification image of the hippocampus counterstained with Fast Red (pink) and immunostained with an antibody against synaptoporin (blue-black). b-d Representative high magnification images of the hilus (b), SMF and IMF (c), and SMF at CA3 (d). e-I Mossy fiber volume in GAP- hoc analysis revealed GAP-43+/- mice had significantly fewer DCX+ cells in the posterior dentate gyrus ( -3.1 to $-3.8 \mathrm{~mm}$ from the Bregma, fig. $1 \mathrm{j}$ ), an area associated with emotion and anxiety [48].

While these data show that P9 mice have decreased indices of neurogenesis (Ki67+ and DCX+ cells), P9 GAP-43+/- did not have decreased GCL volume. This was true either when measured as total GCL volume [mean (in cubic millimeters) \pm SEM,$+/+$ : $7.9 \pm 5.7 ;+/-$ : $7.8 \pm 5.6, \mathrm{p}>0.05$ ] or across the rostrocaudal axis (genotype: $\left.\mathrm{F}_{1,104}=1.0, \mathrm{p}>0.05\right)$.

\section{P9 GAP-43+/- Mice Have Smaller Hilar and}

Suprapyramidal Mossy Fiber Volumes

GAP-43 protein is abundant in growth cones of neuronal axons $[5,6]$ and has been associated with neuropsychiatric disorders in human genetic [54-56] and anatomical studies [57]. Therefore, we hypothesized that P9 GAP-43+/- mice would display abnormal mossy fiber axonal projections from the dentate gyrus to CA3. To visualize the mossy fibers, we stained for synaptoporin, a marker enriched in the mossy fiber tract [fig. 2ad, 45, 58] whose function is necessary for homeostatic regulation of mossy fiber-CA3 synapses [59]. As expected $[45,58]$, strong synaptoporin immunoreactivity was observed in the hilus, the region between the supra- and infrapyramidal blade of the dentate gyrus (fig. 2a, b). Synaptoporin immunoreactivity extended from the hilus in 2 thick axonal bundles - the SMF and IMF - with the SMF projecting to CA3 and abruptly ending at the CA3/CA2 boundary, and the IMF connecting into the SMF (fig. 2a). Stereological quantification of synaptoporin+ mossy fibers in P9 GAP-43+/- versus +/+ mice revealed similar volumes of the entire mossy fiber tract (fig. 2e) and of the mossy fiber subfields: the hilus (fig. 2g), SMF (fig. 2h) and IMF (fig. 2i). However, an analysis that took into account the rostrocaudal axis of the dentate gyrus revealed that GAP-43+/- mice had a smaller volume of synaptoporin+ mossy fibers in the posterior dentate gyrus ( -3.0 to $-3.3 \mathrm{~mm}$ from the Bregma, $\mathrm{p}<0.05$; fig. $2 \mathrm{f}$ ). When analyzed by mossy fiber subfield, GAP-43+/- mice had a smaller volume of hilar
$43+/+$ and $+/-$ mice over the entire GCL (e), in the GCL across Bregma (f), in the entire hilus (g), SMF (h) and IMF (i), and across Bregma in the hilus (j), SMF (k) and IMF (I). Data expressed as means \pm SEM ( $n=5 /$ genotype). e, g-i Analyzed by Student's t test. f, j-I Analyzed by 2 -way ANOVA with Sidak post hoc test. ${ }^{*} \mathrm{p}<$ $0.05,{ }^{* *} \mathrm{p}<0.01$ vs. $+/+$. Scale bars: $\mathbf{a}=100 \mu \mathrm{m}, \mathbf{b}-\mathbf{d}=25 \mu \mathrm{m}$.

(For fig. 2 see next page.)
Latchney/Masiulis/Zaccaria/Lagace/ Powell/McCasland/Eisch 


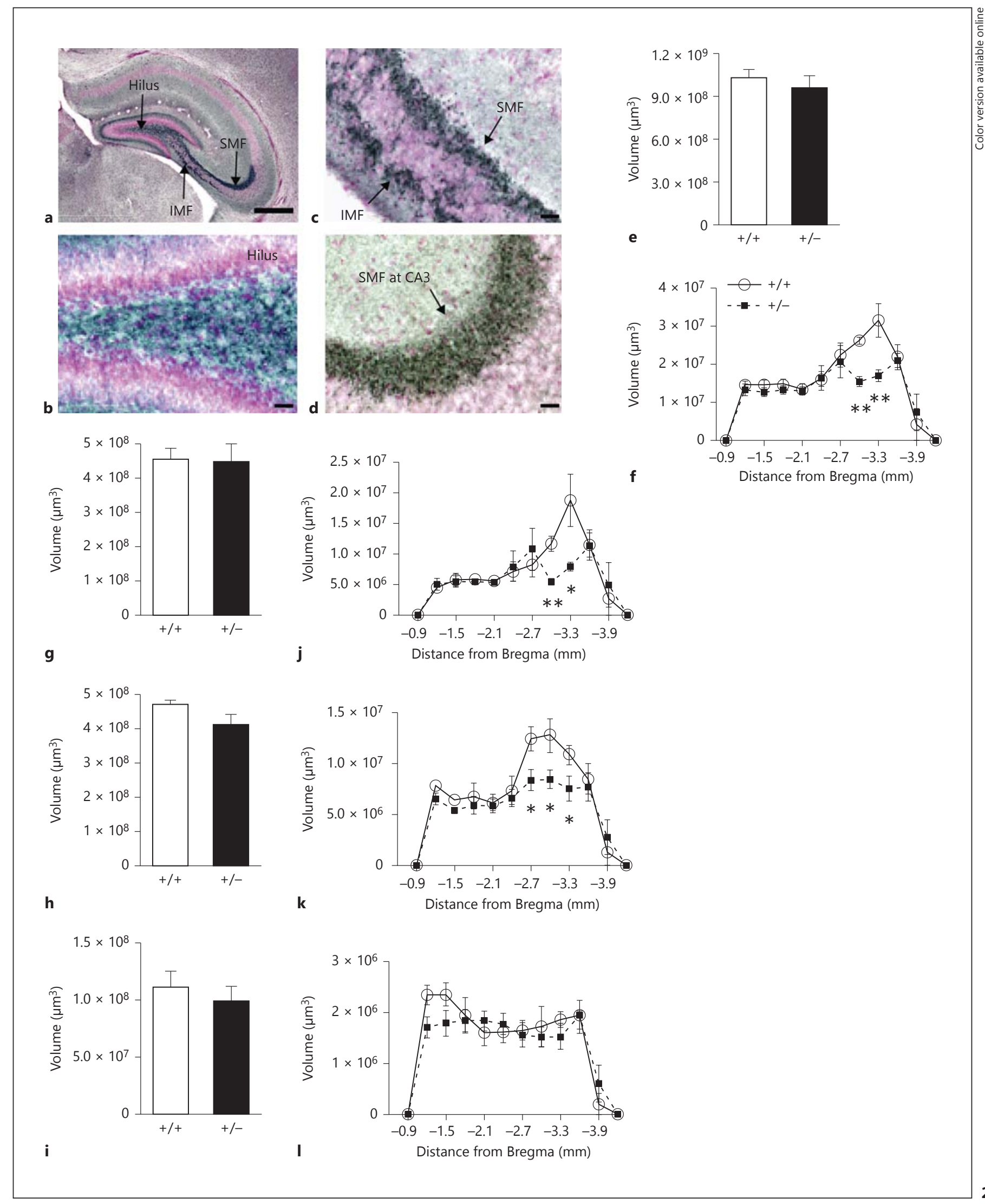


and SMF synaptoporin + tracts in the posterior dentate gyrus $(-2.7$ to $-3.3 \mathrm{~mm}$ from the Bregma, $\mathrm{p}<0.05$; fig. $2 \mathrm{j}, \mathrm{k})$. This posterior region is the same region in which P9 GAP-43+/- mice had reduced DCX+ cell numbers (fig. 1i). The size of the IMF was not different between genotypes (fig. 2l). Taken together, these findings in P9 mice show that in early postnatal development (when hippocampal neurogenesis and axonal pathfinding are robustly active) GAP-43+/- mice have less GCL neurogenesis and a smaller mossy fiber tract compared to $+/+$ mice, particularly in the posterior dentate gyrus.

\section{Male GAP-43+/- Mice Have More Immature}

Neuroblasts at P26

Synaptic remodeling continues well beyond postnatal development and into adulthood [60,61]. Because P9 GAP-43+/- mice had decreased indices of neurogenesis and smaller mossy fiber tract volume, we examined whether these changes in the hippocampal dentate gyrus persisted into adolescence/young adulthood (fig. 3a). In contrast to P9, Ki67+ cells in $+/+$ mice at P26 were restricted to the SGZ (fig. 3b) and were far fewer in number (fig. 3c). This was expected as indices of SGZ proliferation/neurogenesis decrease with age [38]. Also in contrast to P9, P26 GAP-43+/+ and +/mice did not differ in Ki67+ SGZ cell number (fig. 3c). However, when analyzed by sex, P26 male $+/-$ mice had a nonsignificant trend for greater Ki67+ cells versus male $+/+$ mice (fig. $3 \mathrm{~d}$ ). When analyzed across Bregma, P26 male +/- mice had a trend for more Ki67+ cells throughout most of the hippocampal dentate gyrus versus $+/+$ mice ( -0.9 to $-3.6 \mathrm{~mm}$ from the Bregma, fig. $3 \mathrm{e})$. Two-way ANOVA revealed a significant main effect of $\operatorname{Bregma}\left(\mathrm{F}_{11,119}=3.62, \mathrm{p}<0.0001\right)$ and genotype $\left(\mathrm{F}_{1,119}=\right.$ $8.74, \mathrm{p}<0.01)$, but no significant interaction $\left(\mathrm{F}_{11,119}=\right.$ $0.352, \mathrm{p}>0.05)$. No trend was observed in female mice (fig. 3d, f).

We next examined DCX+ GCL cells in P26 mice. Relative to P9, DCX+ cells in P26 +/+ mice were fewer in number and had distinct dendritic processes that ex-

Fig. 3. Male P26 GAP-43+/- mice have increased indices of neurogenesis. a Experimental timeline. Behaviorally naïve GAP$43+/+$ and +/ - mice were killed at P26. b Representative photomicrograph of dentate gyrus counterstained with Fast Red (pink) and immunostained with an antibody against Ki67 (brown). c-f Ki67+ cell number in GAP-43+/- and +/+ mice examined as total number of cells (c), by sex and genotype (d) or over the rostrocaudal axis of the dentate gyrus $(\mathbf{e}, \mathbf{f})$. g Representative photomicrograph tended into the inner molecular layer (fig. 3g). Like P9 mice, however, DCX somal immunoreactivity remained restricted to the outer edge of the cell body. Stereological quantification of DCX + cell number showed no difference between GAP-43+/+ and +/- mice (fig. 3h). However, when analyzed by sex, 2-way ANOVA revealed a significant genotype $\times$ sex interaction $\left(\mathrm{F}_{1,23}=15.48, \mathrm{p}<\right.$ $0.01)$. Post hoc analysis revealed significantly more $\mathrm{DCX}+$ cells in male $+/-$ versus $+/+$ mice (fig. $3 \mathrm{i}, \mathrm{p}<$ $0.01)$. When male $+/+$ and $+/-$ mice were analyzed across Bregma (fig. 3j), there was a significant main effect of Bregma $\left(\mathrm{F}_{11,120}=22.96, \mathrm{p}<0.0001\right)$ and genotype $\left(\mathrm{F}_{1,120}=9.73, \mathrm{p}<0.01\right)$, but no interaction $\left(\mathrm{F}_{11,120}=1.51\right.$, $\mathrm{p}>0.05)$. In contrast to males, there was a trend for fewer DCX+ cells in female $+/-$ versus $+/+$ mice (fig. $3 \mathrm{i}$, $\mathrm{p}=0.09)$. When female $+/+$ and $+/-$ mice were analyzed across Bregma (fig. 3k), there was a significant main effect of Bregma $\left(\mathrm{F}_{11,156}=22.79, \mathrm{p}<0.0001\right)$ and genotype $\left(\mathrm{F}_{1,156}=7.32, \mathrm{p}<0.01\right)$, but no interaction $\left(\mathrm{F}_{11,156}=1.48\right.$, $p>0.05)$.

While these data show that P26 male $+/-$ mice have increased indices of neurogenesis (Ki67+ and DCX+ cells), P26 male GAP-43+/- mice did not have increased GCL volume. This was true either when measured as total GCL volume (mean \pm SEM, +/+: $8.7 \pm 2.0 ;+/-: 10.0 \pm 2.6$, $\mathrm{p}>0.05)$ or across the rostrocaudal axis (genotype: $\left.\mathrm{F}_{1,120}=0.2, \mathrm{p}>0.05\right)$.

\section{P26 GAP-43+/- Mice Have a Larger Volume of Mossy Fiber Projections}

Because the most significant finding in P26 mice occurred in males, we quantified the volume of synaptoporin + mossy fiber axon tract in GAP-43 males (fig. 4a-d). Synaptoporin + mossy fiber axons in P26 mice were of similar distribution compared to P9 mice (fig. 4a-d). Stereological quantification of synaptoporin + mossy fibers in P26 GAP-43+/- versus +/+ mice revealed a significant increase in the size of the total mossy fiber tract (fig. 4e). When analyzed by Bregma, GAP-43+/- mice had larger mossy fiber volume -2.7 to $-3.3 \mathrm{~mm}$ from the Bregma (fig. 2f). When analyzed by hilar, SMF and IMF subfields,

of dentate gyrus counterstained with Fast Red (pink) and immunostained with an antibody against DCX (brown). h-k DCX+ cell number in GAP-43+/- and +/+ mice when examined as total number of cells (h), by sex and genotype (i), and across Bregma in male (j) and female (k) mice. Data expressed as means \pm SEM $(n=5-9 /$ group). c, h Analyzed by Student's t test. $\mathbf{d}-\mathbf{f}$, i-k Analyzed by 2 -way ANOVA with Sidak post hoc test. ${ }^{*} \mathrm{p}<0.05,{ }^{* *} \mathrm{p}<0.01$ vs. $+/+$. Scale bars: $\mathbf{b}, \mathbf{g}=20 \mu \mathrm{m}$.

(For fig. 3 see next page.)
Latchney/Masiulis/Zaccaria/Lagace/ Powell/McCasland/Eisch 


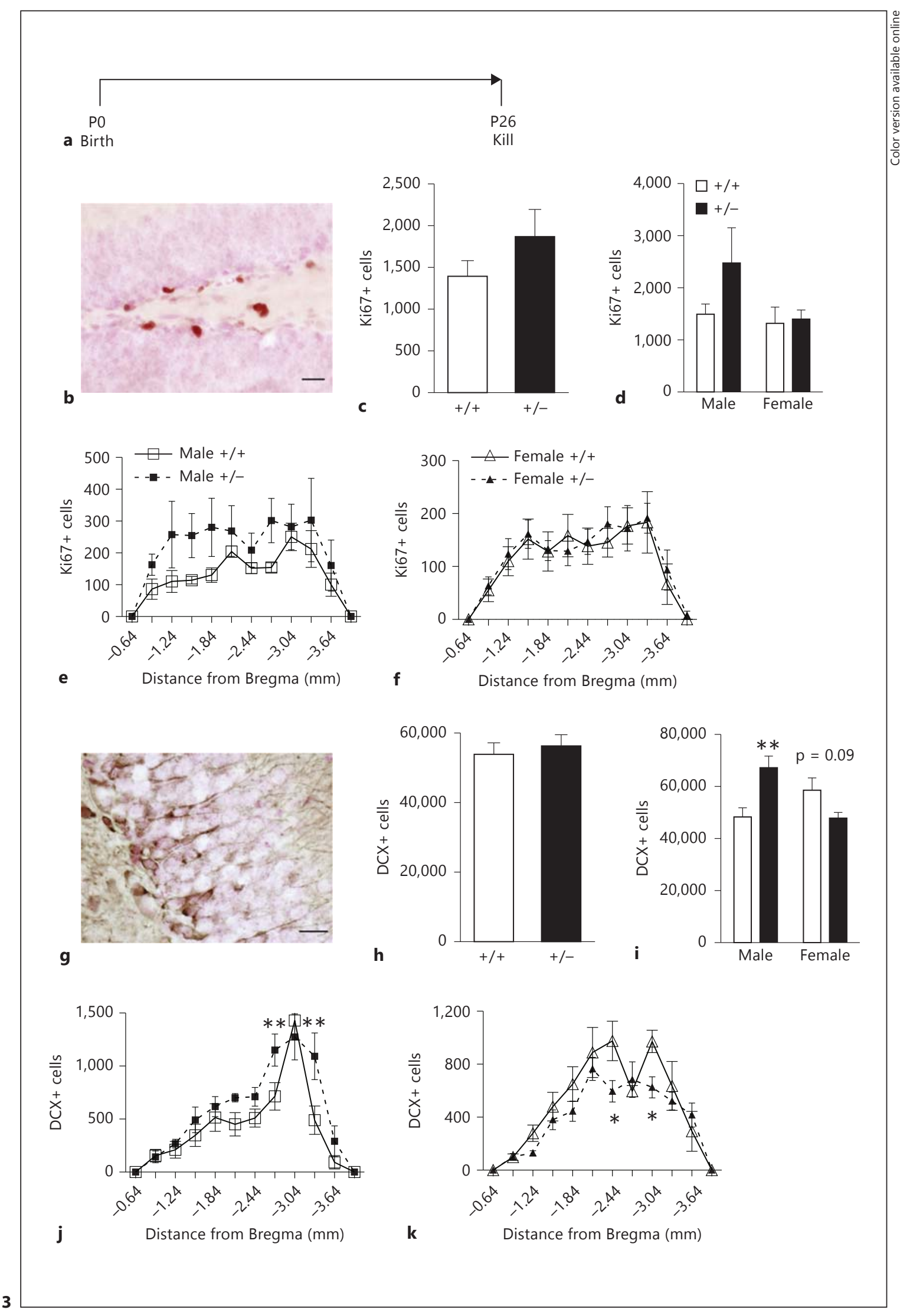




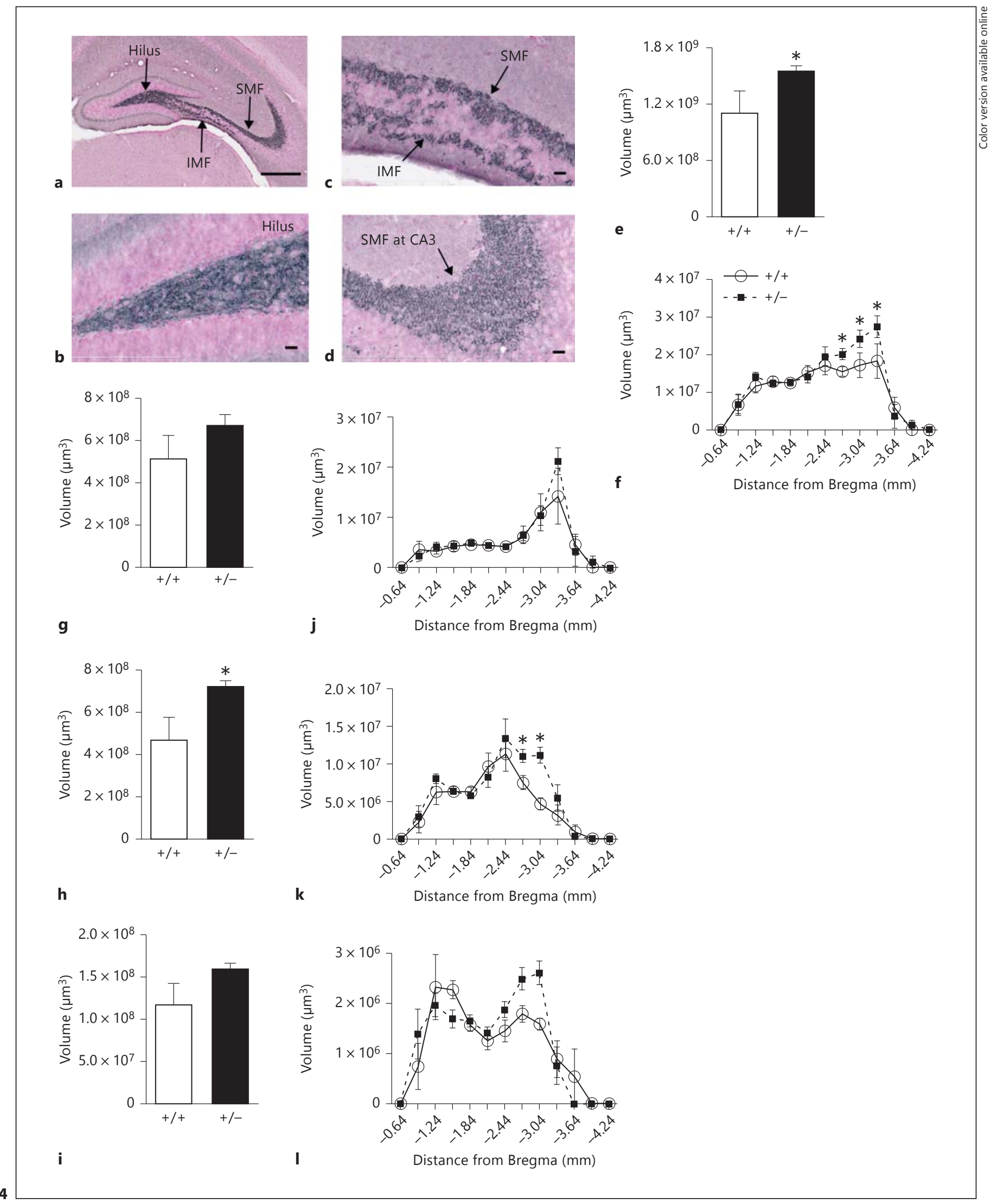

(For legend see next page.) 
Fig. 4. Male P26 GAP-43+/- mice have increased mossy fiber volume in the posterior dentate gyrus. a Representative low magnification image of the hippocampus counterstained with Fast Red (pink) and immunostained with an antibody against synaptoporin (blue-black). b-d Representative high magnification images of the hilus (b), SMF and IMF (c), and SMF at CA3 (d). eI Mossy fiber volume in male GAP-43+/+ and $+/-$ mice over the entire GCL $(\mathbf{e})$, in the GCL across Bregma (f), in the entire hilus (g), SMF (h) and IMF (i), and across Bregma in the hilus (j), SMF (k) and IMF (I). Data expressed as means \pm SEM ( $\mathrm{n}=$ 5-7/genotype). e, g-i Analyzed by Student's t test. f, j-I Analyzed by 2-way ANOVA with Sidak post hoc test. ${ }^{*} \mathrm{p}<0.05$ vs. $+/+$. Scale bars: $\mathbf{a}=100 \mu \mathrm{m}, \mathbf{b}-\mathbf{d}=25 \mu \mathrm{m}$.

Fig. 5. Behaviorally experienced adult GAP-43+/- mice exhibit regionally specific reduction in a key index of neurogenesis. a Experimental timeline. Behavior tests as described in Zaccaria et al. [17] were performed on male and female GAP-43+/and $+/+$ littermates beginning at 4-6 months of age. Following the completion of behavioral tests (5-7 months of age), mice received $1 \mathrm{BrdU}$ injection (150 mg/ kg, i.p.) $2 \mathrm{~h}$ prior to sacrifice. b Representative photomicrograph of dentate gyrus counterstained with Fast Red (pink) and immunostained with an antibody against BrdU (brown). c-e BrdU+ proliferating cells in GAP- $43+/-$ and $+/+$ mice examined as total number of cells (c), by sex and genotype (d), or over the rostrocaudal axis of the dentate gyrus (e). f Representative photomicrograph of dentate gyrus counterstained with Fast Red (pink) and immunostaining with an antibody against DCX (brown). g-i DCX+ cell number in GAP$43+/-$ and $+/+$ mice examined as total number of cells $(\mathbf{g})$, when analyzed by sex and genotype (h) or over the rostrocaudal axis of the dentate gyrus (i). Data expressed as means \pm SEM ( $n=7$ /group). c, $\mathbf{g}$ Analyzed by Student's t test. d, e, h, i Analyzed by 2-way ANOVA with Sidak post hoc test. Scale bars: $\mathbf{b}, \mathbf{f}=50 \mu \mathrm{m}$.

Neurogenesis and Mossy Fiber Volume in GAP-43-Deficient Mice

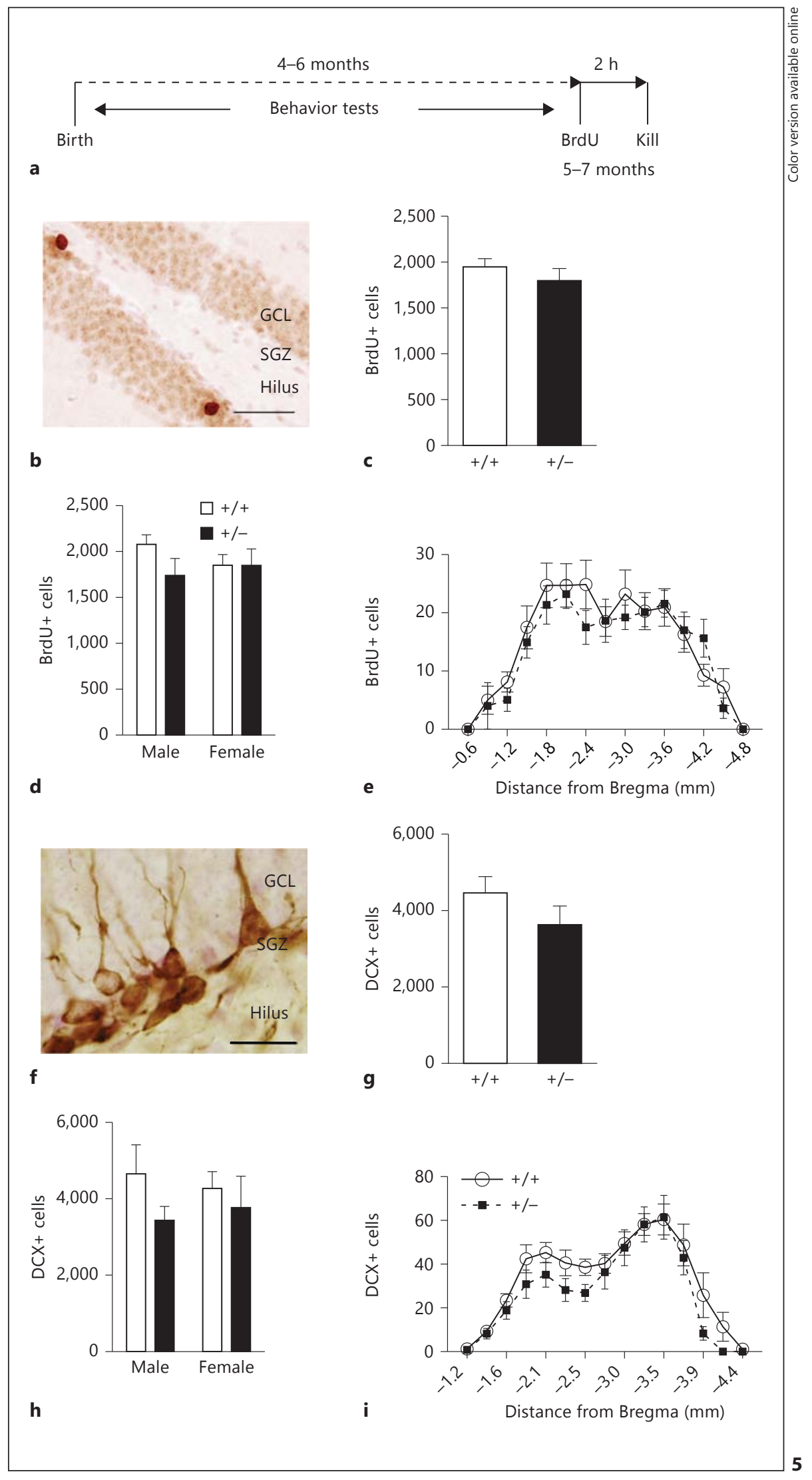

Dev Neurosci 2014;36:44-63 
the SMF volume was greater in P26 GAP-43+/- versus $+/+$ mice (fig. $4 \mathrm{~h}, \mathrm{p}<0.05$ ), but there was no change in hilar (fig. 4g, j) or IMF volume (fig. 4i, l). When male $+/+$ and $+/-$ mice were analyzed across Bregma for the SMF subfield (fig. $4 \mathrm{k}$ ), there was a significant main effect of Bregma $\left(\mathrm{F}_{12,130}=24.89, \mathrm{p}<0.0001\right)$ and genotype $\left(\mathrm{F}_{1,130}=6.43, \mathrm{p}<0.01\right)$, and a near-significant interaction $\left(\mathrm{F}_{12,130}=1.51, \mathrm{p}=0.07\right)$. Collectively, our analyses in P26 GAP-43 mice revealed that (unlike during early postnatal development) male +/- mice have more GCL neurogenesis and a larger synaptoporin + mossy fiber tract compared to $+/+$ mice, particularly in the posterior dentate gyrus.

Behaviorally Experienced 5- to 7-Month-Old GAP43+/- Mice Have Fewer Proliferative DCX+ Cells in the Anterior Dentate Gyrus

Because behavioral testing itself is reported to significantly alter neurogenesis in mice $[62,63]$ and we observed gender differences in hippocampal-dependent behavior [17] and neurogenesis (current study), we were interested in whether neurogenesis in GAP-43+/+ and $+/-$ mice is affected following behavioral testing. GAP- $43+/-$ and $+/+$ littermates were run through behavioral testing at 4-6 months of age, and then given BrdU to label dividing cells $2 \mathrm{~h}$ before kill at 5-7 months of age (fig. 5a) [17]. As expected, BrdU+ cells were mainly located in the SGZ and presented intense, punctate nuclear staining (fig. 5b). There was no difference in BrdU+ cell number (fig. 5c) or BrdU+ cell cluster number (+/+: $555.4 \pm 19.9$; +/-: $556.1 \pm 43.1, \mathrm{p}>0.05)$, or BrdU+ cells/cluster $(+/+: 3.5 \pm 0.1 ;+/-: 3.3 \pm 0.1, \mathrm{p}>$ $0.05)$ in the SGZ of GAP-43+/- versus $+/+$ mice. When analyzed via sex, there was also no difference between genotypes (fig. 5d). Analysis of BrdU+ cell number across the longitudinal axis of the hippocampus revealed a main effect of Bregma ( $p<0.0001$; fig. $5 \mathrm{e}$ ), but no significant difference between genotypes. These data suggest that reduced GAP-43 levels in these behavior-

Fig. 6. Behaviorally experienced adult male, but not female, GAP$43+/$ - mice have fewer proliferative-type DCX+ neuroblasts in the anterior dentate gyrus. $\mathrm{Mol}=$ Molecular layer. a-e Representative images of DCX + cells classified as proliferative $(\mathbf{a}-\mathbf{c})$, intermediate (d) and postmitotic (e) based on dendritic morphology. $\mathbf{f}-\mathbf{m}$ Classification of DCX+ cells as proliferative $(\mathbf{f}, \mathbf{g}, \mathbf{j}, \mathbf{k})$, intermediate (h, I) and postmitotic $(\mathbf{i}, \mathbf{m})$ in male $(\mathbf{f}-\mathbf{i})$ and female $(\mathbf{j}-\mathbf{m}) \mathrm{GAP}-43+/-$ vs. +/+ mice expressed as total cell number $(\mathbf{f}, \mathbf{h}-\mathbf{m})$ or across Bregma $(\mathbf{g}, \mathbf{k}) \cdot \mathbf{n}-\mathbf{u}$ Confirmation of the proliferative $(\mathbf{n}-\mathbf{q})$ vs. postmitotic $(\mathbf{r}-\mathbf{u})$ classification of DCX+ cells (red) in male GAP-43 mice ally experienced mice do not alter proliferation of the SGZ progenitor cell pool.

DCX+ cell counts and dendritic morphology were used to assess the maturation of adult-generated neurons in the dentate gyrus of GAP-43+/- versus +/+ littermates $[43,44]$ (fig. 5f-i, 6a-m). Qualitatively, the number, morphology and distribution of DCX+ GCL neuroblasts in the 5- to 7-month-old behaviorally experienced mice were distinct from those seen in P9 and P26 mice. For example, DCX+cells in 5- to 7-month-old adult $+/+$ mice were far fewer relative to $\mathrm{P} 9$ and $\mathrm{P} 26$, had more extensive dendrites (extending almost to the hippocampal fissure) and presented a darker and more uniform DCX+ somal staining surrounding the entire nucleus. In regard to quantification, the DCX+ cell number was not different in GAP-43+/- mice versus +/+ when examined in the entire GCL (fig. $5 \mathrm{~g}$ ) or in regard to distance from the Bregma (fig. 5i). When analyzed by sex and genotype, there was a nonsignificant trend for fewer DCX+cells in male GAP- $43+/-$ versus +/+ mice (fig. $5 \mathrm{~h}$ ). This trend was not observed in females. To determine if there was a specific change in the maturation of DCX + cells (perhaps contributing to the trend observed in male GAP-43+/mice; fig. 5h). DCX+ cells were then categorized based on their dendritic morphology (fig. 6a-m), which is reflective of their degree of maturity [43]. When examined as total DCX+ GCL cell number, male GAP-43+/- mice had a strong nonsignificant trend $(\mathrm{p}=0.06)$ for fewer proliferative DCX+ cells with no or short $(<10 \mu \mathrm{m})$ processes (fig. 6f) versus $+/+$ mice. When proliferative $\mathrm{DCX}+$ cells were plotted by distance from the Bregma, male GAP-43+/- mice had fewer DCX+cells in the anterior dentate gyrus ( -1.6 to $-2.3 \mathrm{~mm}$ from the Bregma; main effect of genotype: $F_{1,150}=10.67, p<0.01$ ), an area associated with spatial learning [48], compared to male $+/+$ (fig. 6g). This was not observed in females (fig. 6j$\mathrm{m})$. The number of intermediate or postmitotic DCX+ cells with longer processes (fig. $6 \mathrm{~d}, \mathrm{e}$ ) did not differ between genotypes in either sex (fig. 6h, i, l, m).

by presence $(\mathbf{n})$ or absence (r) of colocalization with Ki67 (green). o-q DCX+Ki67+ cells in male GAP-43+/- vs. +/+ mice in the entire GCL $(\mathbf{o})$ or in the anterior $(\mathbf{p})$ and posterior $(\mathbf{q})$ regions of the dentate gyrus. s-u DCX+Ki67- cells in male GAP-43+/- vs. +/+ mice in the entire GCL $(\mathbf{s})$ or in the anterior $(\mathbf{t})$ and posterior $(\mathbf{u})$ regions of the dentate gyrus. Data expressed as means \pm SEM ( $n=$ 7/group). f, h-j, I, m, o-q, s-u Analyzed by Student's t test. g, k Analyzed by 2 -way ANOVA with Sidak post hoc test. ${ }^{*} \mathrm{p}<0.05$ vs. $+/+$. Scale bars: a-e, $\mathbf{n}, \mathbf{r}=20 \mu \mathrm{m}$.

(For fig. 6 see next page.)
Latchney/Masiulis/Zaccaria/Lagace/ Powell/McCasland/Eisch 


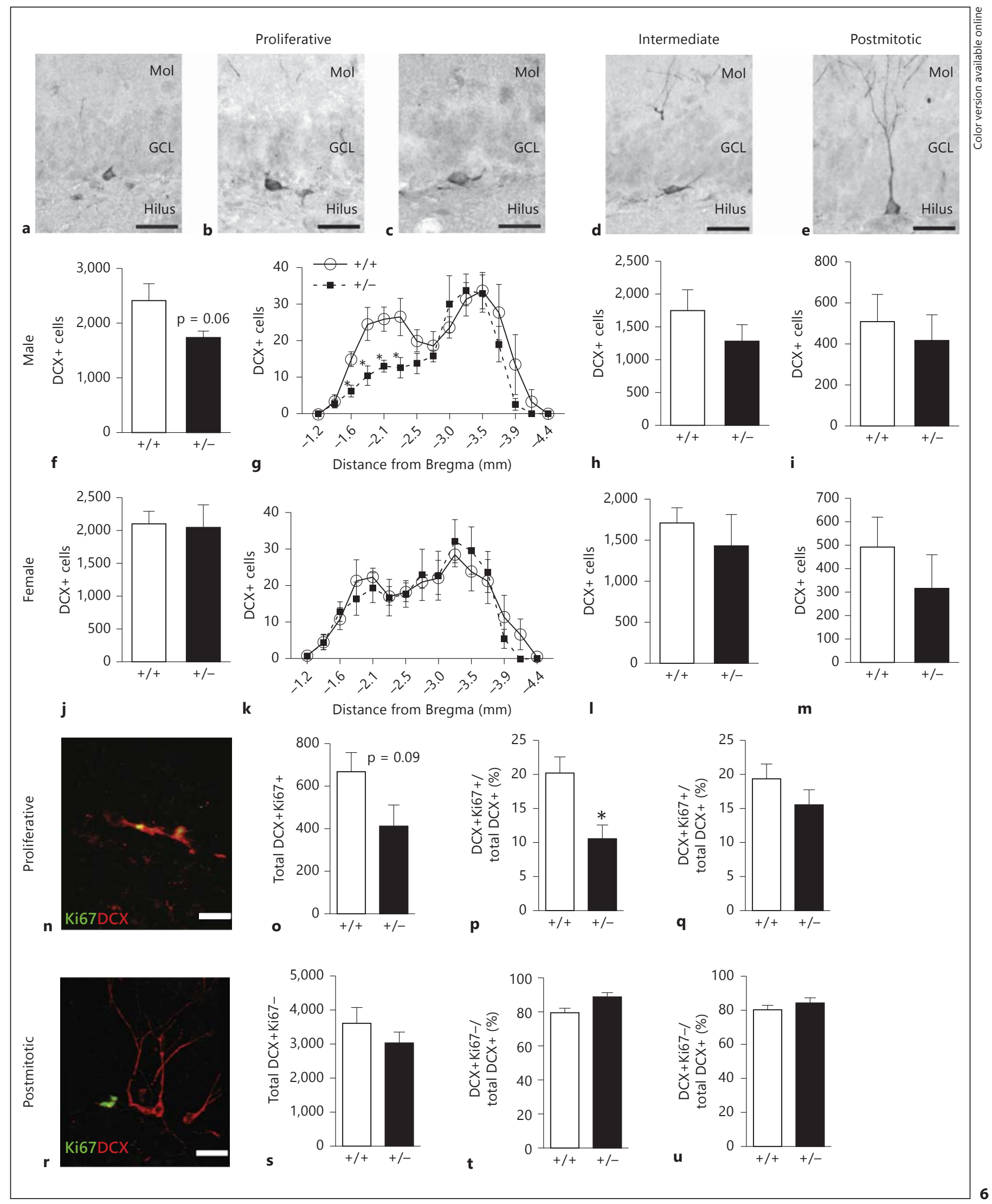

Neurogenesis and Mossy Fiber Volume in 
To confirm the proliferative versus postmitotic identity of DCX+ cells with an independent marker of proliferation, DCX+ cells were also phenotyped based on their coexpression of Ki67 (fig. 6n-u). Using 3D confocal analyses, DCX+ cells with shorter or no dendrites expressed Ki67 (fig. 6n), indicating the proliferative nature of these cells and confirming the dendritic morphology criterion used to classify proliferative DCX+cells in fig. 6a-c [43]. Likewise, DCX+ cells with extensive dendrite branching were Ki67- (fig. 6r), indicating the postmitotic nature of these cells and confirming the dendritic morphology criterion used to classify intermediate (fig. 6d) and postmitotic (fig. 6e) DCX+ cells here and in prior publications [43].

Phenotypic analysis of DCX+Ki67+ cells showed a strong trend for fewer proliferating DCX + cells in male $+/$ - versus $+/+$ male mice (fig. 6o, $\mathrm{p}=0.09$ ). When the dentate gyrus was divided between anterior and posterior regions, there was a $50 \%$ decrease in DCX+Ki67+ cells in the anterior (fig. $6 \mathrm{p}, \mathrm{p}<0.05$ ) but not posterior (fig. 6q), dentate gyrus in male $+/-$ versus $+/+$ mice. No difference was observed in postmitotic DCX $+\mathrm{Ki} 67-$ cell number when the dentate gyrus was examined as a whole (fig. 6s) or when divided into anterior (fig. 6t) and posterior (fig. $6 \mathrm{u}$ ) regions. Additionally, no significant difference in either proliferative or postmitotic DCX+ cells was observed in female mice (data not shown). Collectively, our DCXKi67 colocalization studies confirmed the dendrite morphology data: behaviorally tested 5- to 7-month-old male GAP-43+/- mice have fewer proliferative DCX+cells in the anterior hippocampal dentate gyrus, with no difference or trend seen in postmitotic DCX+ cells in either male or female mice.

\section{Behaviorally Experienced 5- to 7-Month-Old}

GAP-43+/- Mice Have Normal Hippocampal

Mossy Fiber Volume

Synaptoporin + mossy fiber axons in older adult mice were of similar distribution and size as P26 mice (fig. $7 \mathrm{a}-\mathrm{d}$ ). Stereological quantification of synaptoporin + mossy fibers in behaviorally tested 5- to 7-month-

Fig. 7. Hippocampal mossy fiber volume is not altered in behaviorally experienced 5- to 7-month-old GAP-43+/- mice. a Representative low magnification image of the hippocampus counterstained with Fast Red (pink) and immunostained with an antibody against synaptoporin (blue-black). b-d Representative high magnification images of synaptoporin+ staining (blue-black) in the hilus (b), SMF and IMF (c), and SMF at CA3 (d). e-I Mossy fiber volume in old GAP-43+/- versus +/+ mice revealed similar volumes of the entire mossy fiber tract (fig. 7e) and of the hilus (fig. 7g), SMF (fig. 7h) and IMF (fig. 7i). Although there was a main effect across Bregma for each of the mossy fiber subfields analyzed (all 2-way ANOVAs, $\mathrm{p}<$ 0.0001 ), there was no main effect of genotype in any of the mossy fiber subfields (all 2-way ANOVAs, $\mathrm{p}>0.05$; fig. $7 f, j-1$ ) and no significant interaction. The size of the mossy fiber subfields also did not differ when analyzed by gender (data not shown). These data demonstrate that behaviorally tested adult GAP- $43+/-$ and $+/+$ mice have similar volume of synaptoporin + mossy fiber tracts.

\section{Discussion}

Given the link between hippocampal function, neurogenesis and synaptogenesis $[32,33]$, and given that GAP-43+/- mice display impaired spatial learning and stress-induced behavioral features [17], we hypothesized that GAP-43+/- mice would have decreased hippocampal neurogenesis and aberrant or diminished mossy fiber connectivity. However, we found that the developmental impact of GAP-43 deficiency on hippocampal neurogenesis and mossy fiber volume is age dependent. Behaviorally naïve P9 GAP-43+/- mice have fewer proliferating cells and immature neuroblasts and a smaller mossy fiber tract, particularly in the posterior dentate gyrus. In contrast, behaviorally naïve P26 GAP-43+/- mice (particularly males) have more proliferating cells and immature neuroblasts and a larger mossy fiber tract, also in the posterior dentate gyrus. These data highlight a dynamic neurogenic and synaptogenic response to reduced GAP-43 protein levels in the dentate gyrus. Furthermore, as the posterior hippocampus sends projections to areas of the brain largely involved in emotion [48], these disrupted connections in GAP-43+/- mice may contribute to their behavioral phenotype in adulthood [17]. Below we discuss these results, and consider the implications of

GAP $-43+/+$ and $+/-$ mice over the entire GCL (e), in the GCL across Bregma (f), in the entire hilus $(\mathbf{g}), \operatorname{SMF}(\mathbf{h})$ and IMF (i), and across Bregma in the hilus (j), SMF (k) and IMF (I). Data expressed as means \pm SEM ( $\mathrm{n}=7$ /group). $\mathbf{e}, \mathbf{g}-\mathbf{i}$ Analyzed by Student's t test. f, j-I Analyzed by 2-way ANOVA with Sidak post hoc test. Scale bars: $\mathbf{a}=100 \mu \mathrm{m}, \mathbf{b}-\mathbf{d}=25 \mu \mathrm{m}$.

(For fig. 7 see next page.)
Latchney/Masiulis/Zaccaria/Lagace/ Powell/McCasland/Eisch 


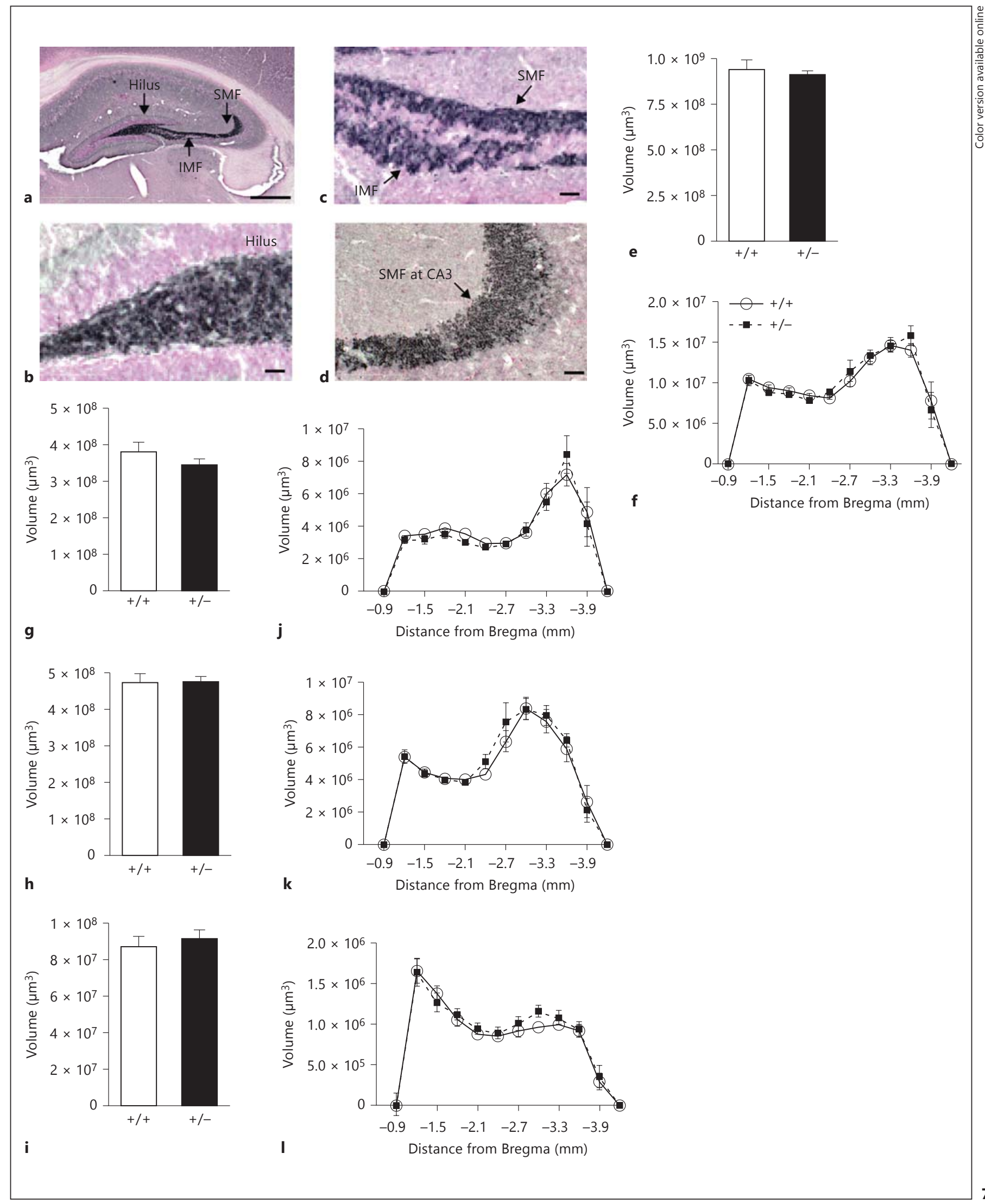


GAP-43+/- mice displaying these striking age-dependent alterations in neurogenesis and mossy fiber tract volume.

Hippocampal Neurogenesis and Synaptogenesis Are Regulated in GAP-43+/- Mice in an Age-Dependent Manner

The most compelling findings presented here are from our behaviorally naïve GAP- $43+/-$ mice in which dentate gyrus neurogenesis and synaptogenesis were transiently and differentially affected with age. P9 GAP$43+/-$ mice have distinct changes in the posterior dentate gyrus: reduced cell proliferation, fewer immature neuroblasts and decreased volume of mossy fibers, which can be interpreted as a redistribution of axons [45]. As GAP-43 protein levels peak at P9 in $+/+$ mice [11] - a developmental time point in mice that coincides with the critical period of axon elongation, terminal arborization and early synaptogenesis [46, 47] - it is reasonable to speculate that a loss of GAP- 43 protein during this critical period significantly diminishes neurogenesis and synaptogenesis. The P9 reductions are also comparable to the developmental delays observed in other brain regions of GAP-43+/- mice $[8,11,64$, 65 ], lending support for its prominent role during development.

Unexpectedly, the reduced neurogenesis and diminished axonal projections in P9 GAP-43+/- mice were reversed with age, such that P26 GAP-43+/- mice displayed increased neurogenesis and greater mossy fiber volume relative to $+/+$ mice, also in the posterior dentate gyrus. One interpretation of this reversal is that it is a compensatory response during adolescence to make up for the reduced neurogenesis and synaptogenesis seen in early postnatal development [our data and 11, $64,66]$. This concept of a compensatory increase or 'rebound' at P26 or later is consistent with what is seen in other brain regions in GAP-43+/- mice $[11,64,66]$. However, our data show an 'overshoot' where there is overcompensation in cell proliferation, number of neuroblasts and mossy fiber volume. Analysis of behaviorally naïve mice at ages older than P26 would clarify if and when the neurogenic and synaptogenic phenotype in $+/-$ mice is fully normalized by compensatory mechanisms.

Another perspective on the increased neurogenesis and mossy fiber volume in P26 $+/-$ mice comes from the literature of normal wild-type $(+/+)$ mice [11], where total GAP-43 protein level is high at P9, drops to much lower levels by P26 and stays low throughout adult- hood. This dynamic fluctuation in total GAP-43 levels does not occur in $+/-$ mice [11], and the GAP-43 levels are actually higher in the cortex of $\mathrm{P} 26+/-$ mice relative to $+/+$ mice [11]. If this dynamic expression pattern of GAP-43 protein also occurs in the hippocampus, the increased neurogenesis and mossy fiber volume in P26 +/- mice may reflect a failure of total GAP-43 protein levels to downregulate into adulthood, allowing for increased neurogenesis and synaptogenesis in $+/$ - relative to +/+ P26 mice. From our data, it is reasonable to propose that the level of GAP-43 protein partially determines the level of neurogenesis and mossy fiber volume: low GAP-43 levels diminish neurogenesis and synaptogenesis, while high levels increase them. This bidirectional regulation of hippocampal neurogenesis and synaptogenesis based on GAP-43 levels complements behavioral studies demonstrating that reduced GAP-43 levels lead to behavioral deficits [17,67], while increased GAP-43 levels enhance behavioral performance [16, 67]. Taken together, our age-dependent findings encourage more exploration of whether fluctuations in GAP-43 levels merely correlate with altered hippocampal neurogenesis, synaptogenesis and behavioral performance, or whether there is a more direct, causative association [64].

\section{Hippocampal Neurogenesis and Reorganization}

of Mossy Fiber Projections in GAP-43+/- Mice:

\section{A Connection?}

The parallel between reduced neurogenesis and mossy fiber projections at P9 and increased neurogenesis and mossy fiber projections at $\mathrm{P} 26$ suggests that neurogenesis may modulate the size of mossy fibers and, in turn, influence hippocampal function. Indeed, prior work has shown that the size of mossy fiber projections positively correlates with behavioral performance $[10,68-71]$ and is dynamically regulated by neurogenic activity $[45,72]$. Therefore, it is conceivable that neurogenesis-induced mossy fiber remodeling may reshape the way in which dentate gyrus granule cells regulate CA3 pyramidal cell activity, which may consequently influence hippocampal-dependent behaviors [73].

There are a number of ways in which neurogenesisinduced mossy fiber remodeling may influence CA3 activity and lead to behavioral adaptations. First, mossy fibers are typically regarded as excitatory projections that synapse onto CA3 pyramidal cells [74]. However, additional studies demonstrate that inhibitory neurons receive about 10 times more synapses from mossy fibers than do principal neurons, generating a net inhibitory
Latchney/Masiulis/Zaccaria/Lagace/ Powell/McCasland/Eisch 
effect onto CA3 [74-76]. Furthermore, young neurons in the GCL can selectively stimulate interneurons in the hilus and CA3 and compete with more mature granule cells for excitatory input [77]. Mossy fiber innervation onto CA3 can also toggle between excitation and inhibition, depending on stimulation dynamics of dentate granule neurons [74]. This underscores the possibility that even slight reorganization of mossy fiber axons (perhaps due to altered neurogenesis) can considerably modify postsynaptic CA3 targets and information processing. Although it remains unknown if and how neurogenesis itself can directly modulate mossy fiber projections and CA3 targets, published work suggests that suppressing neurogenesis during early postnatal development leads to synaptic remodeling between the dentate gyrus and CA3 [78]. In contrast, there are examples in which changes in mossy fiber projections are not associated with changes in neurogenesis [79]. Therefore, it remains to be confirmed in GAP- $43+/-$ mice if changes in hippocampal neurogenesis directly relate to changes in mossy fiber volume.

Second, CA3 pyramidal cells can send reciprocal back-projections to dentate gyrus granule cells $[74,80]$ and possibly regulate neurogenesis [81] and granule cell activity and function [73]. Importantly, ventral CA3 pyramidal cells have 3-4 times as many hilar collateralizations than dorsal CA3 cells $[74,82]$. This is the same septotemporal region in which DCX+cells - immature neuroblasts destined to reach neural maturity and extend mossy fiber axons - were changed in our behaviorally naïve GAP-43+/- mice. CA3 back-projections, whether excitatory or inhibitory, can subsequently lead to increased or decreased cellular activation of immediate early genes in the dentate gyrus [74], emphasizing the complex interplay between pre- and postsynaptic cells throughout the hippocampal synaptic circuit. In addition to immediate early genes, enhanced mossy fiber sprouting also upregulates GAP-43 mRNA expression in dentate gyrus granule cells $[83,84]$, particularly in the ventral hippocampus [84]. This upregulation of GAP-43 expression in the GCL following mossy fiber sprouting supports an active role for this protein in regulating activity-dependent neurogenesis and synaptic plasticity [85].

Adding to the complexity of the mossy fiber circuitry is that mossy fiber axons from granule cells can target various cell types at different distances in the hilus and CA3 [86-88], depending on their location within the GCL. While both P9 and P26 GAP-43+/- mice have a decrease (P9) and then an increase (P26) in mossy fiber tract volume in the posterior hippocampus, P9 GAP-43+/- mice had specific decreases in hilar and SMF volume, while P26 only had increased SMF volume. This age-dependent restructuring of distinct mossy fiber subfields resulting from reduced GAP-43 levels could lead to target-specific alterations in synaptic transmission between the GCL and CA3 $[86,88]$. Although mossy fibers can establish synaptic contact with CA3 pyramidal cell dendrites by P9 $[61,89]$, it is unclear if granule cells develop functional recurrent CA3 collaterals by this age, calling into question the functional contribution of CA3 back-projections and their impact on hippocampal neurogenesis during early postnatal development. Future investigations will be necessary to probe for mechanisms in which neurogenesis-induced mossy fiber alterations may modify CA3 postsynaptic targets and subsequent cellular activation of target genes in the dentate gyrus of GAP$43+$ /- mice.

\section{Hippocampal Neurogenesis and Synaptic Plasticity in GAP-43+/- and +/+ Mice following Behavioral Testing}

Behavioral testing itself significantly alters neurogenesis in mice $[62,63]$. However, given both our prior behavioral results with GAP-43+/- mice [17] and the age-dependent changes we see in these measures in behaviorally naïve P9 versus P26 GAP-43+/- mice, we felt it was important to report here our findings in behaviorally tested 5- to 7-month-old male GAP-43+/- versus $+/+$ mice (fewer proliferative-type immature neuroblasts in the anterior dentate gyrus). These data have their limitations, in that they are restricted to the anterior dentate gyrus and are from behaviorally tested mice (fig. 5-7), making it imprudent to connect those to our data in behaviorally naïve mice P9 and P26 mice (fig. 1-4). However, it is still reasonable to briefly comment on these data from 5- to 7-month-old behaviorally tested mice. As we show an age-induced fluctuation in neurogenesis and mossy fiber volume in behaviorally naïve GAP-43+/- mice (P9 decrease, P26 increase), it is possible that the decrease seen in 5- to 7-month-old mice is a continuation of that dynamic pattern. Perhaps, for example, neurogenesis falls again in adulthood in GAP-43+/- mice after the initial compensatory increase seen at P26 is over and GAP-43 levels in GAP-43+/mice returns to lower than seen in GAP-43+/+. However, we feel this is unlikely given that GAP-43 levels are the probably the main driver behind the changes seen at P9 and P26, and by P30 and into later adulthood the 
levels of GAP-43 remain low [11]. Thus, it is possible that the decreased neuroblast number is merely a remnant of more robust age-induced alterations in neurogenesis, but that these are masked by extensive behavior testing.

The points raised above are particularly important to consider because GAP-43+/- mice exhibited abnormal hippocampal neurogenesis and synaptogenesis during development (current study) and exhibited impaired cognition in several hippocampal-dependent tasks as adults [17]. These behavioral tasks principally rely on the anterior hippocampus [48], and so behavioral testing performed may indeed have influenced the outcome of our data (fig. 5-7). Furthermore, our prior study demonstrated that GAP- $43+/-$ males were more susceptible than GAP-43+/- females to stress-induced behavioral withdrawal and anxiety [17]. Interestingly, new neurons in the hippocampus may be functionally important in an animal's ability to respond to stress $[28,30$, 31 ] and immature DCX+ neurons are known to be vulnerable to stress [90]. Therefore, the male-specific decrease in DCX+ cells in these animals could account for the increased susceptibility to stress in GAP-43+/- male mice. However, it is challenging to interpret our adult data because hippocampal-dependent tasks can alter neurogenesis [62, 63]. For example, hippocampal-dependent tasks that actively engage learning and memory processes can stimulate neurogenesis [63]. In contrast, experimenter manipulation and unpredictable stress, which occur during behavioral testing, can suppress neurogenesis [25]. Therefore, an equivalent study in around 5- to 7-month-old behaviorally naïve mice is needed to see how much the decreased DCX+ number seen in behaviorally tested GAP-43+/- male mice is due to merely age-induced fluctuations, behavioral experience or a combination.
The 'Disordered Connectivity' Hypothesis:

Cytological, Anatomical and Behavioral

Correlations in GAP-43+/- Mice

In sum, our results show that behaviorally naïve GAP-43+/- mice have an age-dependent abnormal fluctuation in hippocampal neurogenesis and mossy fiber connectivity, possibly contributing to the GAP-43+/behavioral phenotype [17]. Our results also show that the 'disordered connectivity' hypothesis of GAP-43+/mice applies not only to the cortex and thalamus $[8,11$, 13, 64-66] but also to the dentate gyrus. As disordered axonal connectivity is seen in many developmental disorders and animal models of these disorders [57, 91-93], it is perhaps not surprising that GAP- $43+/$ - showed behavioral symptoms such as resistance to change and vulnerability to stress [17]. In other words, if the neural connections are disturbed, predictable behavioral changes emerge. This probable link encourages further investigations into this mouse model, including more detailed anatomical and cytological characterization of brain structures that are affected in neuropsychiatric conditions that are marked by anxiety, deficits in communication and social interaction, and sensory and cognitive impairments.

\section{Acknowledgments}

This work was supported by grants to A.J.E. from the NIH (DA 0167565, DA 016765-07S1, DA 023555) and NASA (NNX12AB55G). S.E.L. is supported by a Diversity Fellowship (DA 016765-09S1) from AJE's NIH R01 grant. I.M. was supported by a postdoctoral fellowship on a Ruth L. Kirschstein National Research Service Award (NRSA) Institutional Research T32 Training Grant (T32DA 007290) from the NIDA. We thank Ginny Grieb for excellent technical assistance and astounding resourcefulness in regard to location of tissue samples.

\section{References}

-1 Ebert DH, Greenberg ME: Activity-dependent neuronal signalling and autism spectrum disorder. Nature 2013;493:327-337.

- Duman RS, Aghajanian GK: Synaptic dysfunction in depression: potential therapeutic targets. Science 2012;338:68-72.

3 Chakrabarti L, Galdzicki Z, Haydar TF: Defects in embryonic neurogenesis and initial synapse formation in the forebrain of the Ts65Dn mouse model of Down syndrome. J Neurosci 2007;27:11483-11495.

4 Bassell GJ, Warren ST: Fragile X syndrome: loss of local mRNA regulation alters synaptic development and function. Neuron 2008;60: 201-214.

5 Benowitz LI, Routtenberg A: GAP-43: an intrinsic determinant of neuronal development and plasticity. Trends Neurosci 1997;20:8491.

6 6 Denny JB: Molecular mechanisms, biological actions, and neuropharmacology of the growth-associated protein GAP-43. Curr Neuropharmacol 2006;4:293-304.

-7 Grasselli G, Mandolesi G, Strata P, Cesare P: Impaired sprouting and axonal atrophy in cerebellar climbing fibres following in vivo si- lencing of the growth-associated protein GAP-43. PLoS One 2011;6:e20791.

-8 Mcllvain VA, Robertson DR, Maimone MM, McCasland JS: Abnormal thalamocortical pathfinding and terminal arbors lead to enlarged barrels in neonatal GAP-43 heterozygous mice. J Comp Neurol 2003;462:252-264.

9 Maier DL, Mani S, Donovan SL, Soppet D, Tessarollo L, McCasland JS, Meiri KF: Disrupted cortical map and absence of cortical barrels in growth-associated protein (GAP)43 knockout mice. Proc Natl Acad Sci USA 1999;96:9397-9402.
60

Dev Neurosci 2014;36:44-63 DOI: $10.1159 / 000357840$
Latchney/Masiulis/Zaccaria/Lagace/ Powell/McCasland/Eisch 
10 Holahan MR, Honegger KS, Routtenberg A: Ectopic growth of hippocampal mossy fibers in a mutated GAP-43 transgenic mouse with impaired spatial memory retention. Hippocampus 2010;20:58-64.

11 Mcllvain V, McCasland JS: GAP-43 heterozygous mice show delayed barrel patterning, differentiation of radial glia, and downregulation of GAP-43. Anat Rec A Discov Mol Cell Evol Biol 2006;288:143-157.

12 Gozzi M, Nielson DM, Lenroot RK, Ostuni JL, Luckenbaugh DA, Thurm AE, Giedd JN, Swedo SE: A magnetization transfer imaging study of corpus callosum myelination in young children with autism. Biol Psychiatry 2012;72:215-220.

-13 Shen Y, Mani S, Donovan SL, Schwob JE, Meiri KF: Growth-associated protein-43 is required for commissural axon guidance in the developing vertebrate nervous system. J Neurosci 2002;22:239-247.

14 Holahan M, Routtenberg A: The protein kinase $\mathrm{C}$ phosphorylation site on GAP-43 differentially regulates information storage. Hippocampus 2008;18:1099-1102.

-15 Holahan MR, Honegger KS, Tabatadze N, Routtenberg A: GAP-43 gene expression regulates information storage. Learn Mem 2007; 14:407-415.

16 Routtenberg A, Cantallops I, Zaffuto S, Serrano $P$, Namgung $U$ : Enhanced learning after genetic overexpression of a brain growth protein. Proc Natl Acad Sci USA 2000;97:76577662.

17 Zaccaria KJ, Lagace DC, Eisch AJ, McCasland JS: Resistance to change and vulnerability to stress: autistic-like features of GAP43-deficient mice. Genes Brain Behav 2010;9:985996.

18 Li Y, Mu Y, Gage FH: Development of neural circuits in the adult hippocampus. Curr Top Dev Biol 2009;87:149-174.

19 Altman J, Bayer SA: Migration and distribution of two populations of hippocampal granule cell precursors during the perinatal and postnatal periods. J Comp Neurol 1990;301: 365-381.

20 Li G, Pleasure SJ: Morphogenesis of the dentate gyrus: what we are learning from mouse mutants. Dev Neurosci 2005;27:93-99.

-21 Mitchell BD, Emsley JG, Magavi SS, Arlotta P, Macklis JD: Constitutive and induced neurogenesis in the adult mammalian brain: manipulation of endogenous precursors toward CNS repair. Dev Neurosci 2004;26: 101-117.

22 Hastings NB, Gould E: Rapid extension of axons into the CA3 region by adult-generated granule cells. J Comp Neurol 1999;413:146154.

23 Markakis EA, Gage FH: Adult-generated neurons in the dentate gyrus send axonal projections to field CA3 and are surrounded by synaptic vesicles. J Comp Neurol 1999;406:449460.
4 Li G, Berger O, Han SM, Paredes M, Wu NC, Pleasure SJ: Hilar mossy cells share developmental influences with dentate granule neurons. Dev Neurosci 2008;30:255-261.

25 Petrik D, Lagace DC, Eisch AJ: The neurogenesis hypothesis of affective and anxiety disorders: are we mistaking the scaffolding for the building? Neuropharmacology 2012;62:21-34.

26 Guo W, Allan AM, Zong R, Zhang L, Johnson EB, Schaller EG, Murthy AC, Goggin SL, Eisch AJ, Oostra BA, Nelson DL, Jin P, Zhao $\mathrm{X}$ : Ablation of Fmrp in adult neural stem cells disrupts hippocampus-dependent learning. Nat Med 2011;17:559-565.

27 McHugh TJ, Jones MW, Quinn JJ, Balthasar N, Coppari R, Elmquist JK, Lowell BB, Fanselow MS, Wilson MA, Tonegawa S: Dentate gyrus NMDA receptors mediate rapid pattern separation in the hippocampal network. Science 2007;317:94-99.

28 Lagace DC, Donovan MH, DeCarolis NA, Farnbauch LA, Malhotra S, Berton O, Nestler EJ, Krishnan V, Eisch AJ: Adult hippocampal neurogenesis is functionally important for stress-induced social avoidance. Proc Natl Acad Sci USA 2010;107:4436-4441.

29 Oomen CA, Soeters H, Audureau N, Vermunt L, van Hasselt FN, Manders EM, Joels M, Lucassen PJ, Krugers H: Severe early life stress hampers spatial learning and neurogenesis, but improves hippocampal synaptic plasticity and emotional learning under highstress conditions in adulthood. J Neurosci 2010;30:6635-6645.

30 Snyder JS, Soumier A, Brewer M, Pickel J, Cameron HA: Adult hippocampal neurogenesis buffers stress responses and depressive behaviour. Nature 2011;476:458-461.

- 31 Lyons DM, Buckmaster PS, Lee AG, Wu C, Mitra R, Duffey LM, Buckmaster CL, Her S, Patel PD, Schatzberg AF: Stress coping stimulates hippocampal neurogenesis in adult monkeys. Proc Natl Acad Sci USA 2010;107: 14823-14827.

32 Clelland CD, Choi M, Romberg C, Clemenson GD Jr, Fragniere A, Tyers P, Jessberger S, Saksida LM, Barker RA, Gage FH, Bussey TJ: A functional role for adult hippocampal neurogenesis in spatial pattern separation. Science 2009;325:210-213.

33 Stone SS, Teixeira CM, Zaslavsky K, Wheeler AL, Martinez-Canabal A, Wang AH, Sakaguchi M, Lozano AM, Frankland PW: Functional convergence of developmentally and adultgenerated granule cells in dentate gyrus circuits supporting hippocampus-dependent memory. Hippocampus 2011;21:1348-1362.

34 Mandyam CD, Harburg GC, Eisch AJ: Determination of key aspects of precursor cell proliferation, cell cycle length and kinetics in the adult mouse subgranular zone. Neuroscience 2007;146:108-122.

35 Ables JL, Decarolis NA, Johnson MA, Rivera PD, Gao Z, Cooper DC, Radtke F, Hsieh J, Eisch AJ: Notch1 is required for maintenance of the reservoir of adult hippocampal stem cells. J Neurosci 2010;30:10484-10492.
36 Lagace DC, Whitman MC, Noonan MA, Ables JL, DeCarolis NA, Arguello AA, Donovan $\mathrm{MH}$, Fischer SJ, Farnbauch LA, Beech RD, DiLeone RJ, Greer CA, Mandyam CD, Eisch AJ: Dynamic contribution of nestin-expressing stem cells to adult neurogenesis. J Neurosci 2007;27:12623-12629.

37 Mandyam CD, Norris RD, Eisch AJ: Chronic morphine induces premature mitosis of proliferating cells in the adult mouse subgranular zone. J Neurosci Res 2004;76:783794.

38 Gilley JA, Yang CP, Kernie SG: Developmental profiling of postnatal dentate gyrus progenitors provides evidence for dynamic cellautonomous regulation. Hippocampus 2011; 21:33-47.

39 Raman L, Kong X, Gilley JA, Kernie SG Chronic hypoxia impairs murine hippocampal development and depletes the postnatal progenitor pool by attenuating mammalian target of rapamycin signaling. Pediatr Res 2011;70:159-165.

40 West MJ, Gundersen HJ: Unbiased stereological estimation of the number of neurons in the human hippocampus. J Comp Neurol 1990;296:1-22.

41 Mouton P: Principles and Practices of Unbiased Stereology: An Introduction for Bioscientists. Baltimore, John Hopkins University Press, 2002.

-42 Eisch AJ, Barrot M, Schad CA, Self DW, Nestler EJ: Opiates inhibit neurogenesis in the adult rat hippocampus. Proc Natl Acad Sci USA 2000;97:7579-7584.

43 Plumpe T, Ehninger D, Steiner B, Klempin F, Jessberger S, Brandt M, Romer B, Rodriguez GR, Kronenberg G, Kempermann G: Variability of doublecortin-associated dendrite maturation in adult hippocampal neurogenesis is independent of the regulation of precursor cell proliferation. BMC Neurosci 2006; 7:77.

44 Paus M, Kohl Z, Ben Abdallah NM, Galter D, Gillardon F, Winkler J: Enhanced dendritogenesis and axogenesis in hippocampal neuroblasts of LRRK2 knockout mice. Brain Res 2013;1497:85-100.

45 Romer B, Krebs J, Overall RW, Fabel K, Babu $\mathrm{H}$, Overstreet-Wadiche L, Brandt MD, Williams RW, Jessberger S, Kempermann G: Adult hippocampal neurogenesis and plasticity in the infrapyramidal bundle of the mossy fiber projection. I. Co-regulation by activity. Front Neurosci 2011;5:107.

46 Bayer SA: Development of the hippocampal region in the rat. I. Neurogenesis examined with $3 \mathrm{H}$-thymidine autoradiography. J Comp Neurol 1980;190:87-114.

47 Bayer SA: Development of the hippocampal region in the rat. II. Morphogenesis during embryonic and early postnatal life. J Comp Neurol 1980;190:115-134.

48 Sahay A, Hen R: Adult hippocampal neurogenesis in depression. Nat Neurosci 2007;10: 1110-1115. 
49 Fujise N, Liu Y, Hori N, Kosaka T: Distribution of calretinin immunoreactivity in the mouse dentate gyrus. II. Mossy cells, with special reference to their dorsoventral difference in calretinin immunoreactivity. Neuroscience 1998;82:181-200.

50 Liu Y, Fujise N, Kosaka T: Distribution of calretinin immunoreactivity in the mouse dentate gyrus. I. General description. Exp Brain Res 1996;108:389-403.

51 Jinno S, Kosaka T: Patterns of expression of neuropeptides in GABAergic nonprincipal neurons in the mouse hippocampus: quantitative analysis with optical disector. J Comp Neurol 2003;461:333-349.

52 Sloviter RS, Lomo T: Updating the lamellar hypothesis of hippocampal organization. Front Neural Circuits 2012;6:102.

53 Gage FH, Thompson RG: Differential distribution of norepinephrine and serotonin along the dorsal-ventral axis of the hippocampal formation. Brain Res Bull 1980;5: 771-773.

-54 Allen-Brady K, Miller J, Matsunami N, Stevens J, Block H, Farley M, Krasny L, Pingree C, Lainhart J, Leppert M, McMahon WM, Coon H: A high-density SNP genome-wide linkage scan in a large autism extended pedigree. Mol Psychiatry 2009; 14: 590-600.

-55 Shuvarikov A, Campbell IM, Dittwald P, Neill NJ, Bialer MG, Moore C, Wheeler PG, Wallace SE, Hannibal MC, Murray MF, Giovanni MA, Terespolsky D, Sodhi S, Cassina M, Viskochil D, Moghaddam B, Herman K, Brown CW, Beck CR, Gambin A, Cheung SW, Patel A, Lamb AN, Shaffer LG, Ellison JW, Ravnan JB, Stankiewicz P, Rosenfeld JA: Recurrent HERV-H-mediated 3q13.2-q13.31 deletions cause a syndrome of hypotonia and motor, language, and $\operatorname{cog}$ nitive delays. Hum Mutat 2013;34:14151423.

-56 Molin AM, Andrieux J, Koolen DA, Malan V, Carella M, Colleaux L, Cormier-Daire V, David A, de Leeuw N, Delobel B, Duban-Bedu B, Fischetto R, Flinter F, Kjaergaard S, Kok F, Krepischi AC, Le Caignec C, Ogilvie CM, Maia S, Mathieu-Dramard M, Munnich A, Palumbo O, Papadia F, Pfundt R, Reardon W, Receveur A, Rio M, Ronsbro Darling L, Rosenberg C, Sa J, Vallee L, Vincent-Delorme C, Zelante L, Bondeson ML, Anneren G: A novel microdeletion syndrome at $3 \mathrm{q} 13.31$ characterised by developmental delay, postnatal overgrowth, hypoplastic male genitals, and characteristic facial features. J Med Genet 2012;49:104-109.

57 Zikopoulos B, Barbas H: Changes in prefrontal axons may disrupt the network in autism. J Neurosci 2010;30:14595-14609.

-58 Singec I, Knoth R, Ditter M, Hagemeyer CE, Rosenbrock H, Frotscher M, Volk B: Synaptic vesicle protein synaptoporin is differently expressed by subpopulations of mouse hippocampal neurons. J Comp Neurol 2002;452: 139-153.
59 Lee KJ, Queenan BN, Rozeboom AM, Bellmore R, Lim ST, Vicini S, Pak DT: Mossy fiber-CA3 synapses mediate homeostatic plasticity in mature hippocampal neurons. Neuron 2013;77:99-114.

60 Galimberti I, Gogolla N, Alberi S, Santos AF, Muller D, Caroni P: Long-term rearrangements of hippocampal mossy fiber terminal connectivity in the adult regulated by experience. Neuron 2006;50:749-763.

61 Wilke SA, Antonios JK, Bushong EA, Badkoobehi A, Malek E, Hwang M, Terada M, Ellisman $\mathrm{MH}$, Ghosh A: Deconstructing complexity: serial block-face electron microscopic analysis of the hippocampal mossy fiber synapse. J Neurosci 2013;33:507-522.

62 Snyder JS, Clifford MA, Jeurling SI, Cameron HA: Complementary activation of hippocampal-cortical subregions and immature neurons following chronic training in single and multiple context versions of the water maze. Behav Brain Res 2012;227:330339.

63 Snyder JS, Radik R, Wojtowicz JM, Cameron HA: Anatomical gradients of adult neurogenesis and activity: young neurons in the ventral dentate gyrus are activated by water maze training. Hippocampus 2009;19:360370.

64 Kelly EA, Tremblay ME, McCasland JS, Majewska AK: Postsynaptic deregulation in GAP-43 heterozygous mouse barrel cortex. Cereb Cortex 2010;20:1696-1707.

65 Zaccaria KJ, McCasland JS: Emergence of layer IV barrel cytoarchitecture is delayed in somatosensory cortex of GAP-43 deficient mice following delayed development of dendritic asymmetry. Somatosens Mot Res 2012;29:7788.

66 Dubroff JG, Stevens RT, Hitt J, Hodge CJ Jr, McCasland JS: Anomalous functional organization of barrel cortex in GAP-43 deficient mice. Neuroimage 2006;29:10401048.

67 Rekart JL, Meiri K, Routtenberg A: Hippocampal-dependent memory is impaired in heterozygous GAP-43 knockout mice. Hippocampus 2005;15:1-7.

68 Crusio WE, Schwegler H: Learning spatial orientation tasks in the radial-maze and structural variation in the hippocampus in inbred mice. Behav Brain Funct 2005;1:3.

69 Bhatti AS, Hall P, Ma Z, Tao R, Isgor C: Hippocampus modulates the behaviorally sensitizing effects of nicotine in a rat model of novelty-seeking: potential role for mossy fibers. Hippocampus 2007;17:922-933.

70 Crusio WE, Schwegler H, Lipp HP: Radialmaze performance and structural variation of the hippocampus in mice: a correlation with mossy fibre distribution. Brain Res 1987;425: 182-185.

71 Roullet P, Lassalle JM: Genetic variation, hippocampal mossy fibres distribution, novelty reactions and spatial representation in mice. Behav Brain Res 1990;41:61-70.
72 Llorens-Martin M, Teixeira CM, FusterMatanzo A, Jurado-Arjona J, Borrell V, Soriano E, Avila J, Hernandez F: Tau isoform with three microtubule binding domains is a marker of new axons generated from the subgranular zone in the hippocampal dentate gyrus: implications for Alzheimer's disease. J Alzheimers Dis 2012;29:921930.

73 Jinde S, Zsiros V, Jiang Z, Nakao K, Pickel J, Kohno K, Belforte JE, Nakazawa K: Hilar mossy cell degeneration causes transient dentate granule cell hyperexcitability and impaired pattern separation. Neuron 2012;76: 1189-1200.

74 Scharfman HE: The CA3 'backprojection' to the dentate gyrus. Prog Brain Res 2007;163: 627-637.

75 Schmidt B, Marrone DF, Markus EJ: Disambiguating the similar: the dentate gyrus and pattern separation. Behav Brain Res 2012;226: 56-65.

-76 Acsady L, Kamondi A, Sik A, Freund T, Buzsaki G: GABAergic cells are the major postsynaptic targets of mossy fibers in the rat hippocampus. J Neurosci 1998;18:33863403.

77 Lacefield CO, Itskov V, Reardon T, Hen R, Gordon JA: Effects of adult-generated granule cells on coordinated network activity in the dentate gyrus. Hippocampus 2012;22:106116.

78 Yasuda M, Johnson-Venkatesh EM, Zhang H, Parent JM, Sutton MA, Umemori H: Multiple forms of activity-dependent competition refine hippocampal circuits in vivo. Neuron 2011;70:1128-1142.

-79 Bender RA, Dube C, Gonzalez-Vega R, Mina EW, Baram TZ: Mossy fiber plasticity and enhanced hippocampal excitability, without hippocampal cell loss or altered neurogenesis, in an animal model of prolonged febrile seizures. Hippocampus 2003; 13:399-412.

80 Vivar C, Potter MC, Choi J, Lee JY, Stringer TP, Callaway EM, Gage FH, Suh H, van Praag H: Monosynaptic inputs to new neurons in the dentate gyrus. Nat Commun 2012;3:1107.

81 Liu JX, Pinnock SB, Herbert J: Novel control by the CA3 region of the hippocampus on neurogenesis in the dentate gyrus of the adult rat. PLoS One 2011;6:e17562.

82 Ishizuka N, Weber J, Amaral DG: Organization of intrahippocampal projections originating from CA3 pyramidal cells in the rat. J Comp Neurol 1990;295:580-623.

83 Meberg PJ, Gall CM, Routtenberg A: Induction of F1/GAP-43 gene expression in hippocampal granule cells after seizures (corrected). Brain Res Mol Brain Res 1993;17:295299.

84 Cantallops I, Routtenberg A: Rapid induction by kainic acid of both axonal growth and $\mathrm{F} 1 /$ GAP-43 protein in the adult rat hippocampal granule cells. J Comp Neurol 1996;366:303319 
85 Han MH, Jiao S, Jia JM, Chen Y, Chen CY, Gucek M, Markey SP, Li Z: The novel caspase-3 substrate Gap43 is involved in AMPA receptor endocytosis and long-term depression. Mol Cell Proteomics 2013;12:37193731.

86 McBain CJ: Differential mechanisms of transmission and plasticity at mossy fiber synapses. Prog Brain Res 2008;169:225-240.

87 Claiborne BJ, Amaral DG, Cowan WM: A light and electron microscopic analysis of the mossy fibers of the rat dentate gyrus. J Comp Neurol 1986;246:435-458.

88 Amaral DG, Scharfman HE, Lavenex P: The dentate gyrus: fundamental neuroanatomical organization (dentate gyrus for dummies) Prog Brain Res 2007;163:3-22.
Amaral DG, Dent JA: Development of the mossy fibers of the dentate gyrus. I. A light and electron microscopic study of the mossy fibers and their expansions. J Comp Neurol 1981;195:51-86.

90 Eisch AJ, Cameron HA, Encinas JM, Meltzer LA, Ming GL, Overstreet-Wadiche LS: Adult neurogenesis, mental health, and mental illness: hope or hype? J Neurosci 2008;28: 11785-11791.
91 Just MA, Cherkassky VL, Keller TA, Kana RK, Minshew NJ: Functional and anatomical cortical underconnectivity in autism: evidence from an FMRI study of an executive function task and corpus callosum morphometry. Cereb Cortex 2007;17:951961.

92 Just MA, Cherkassky VL, Keller TA, Minshew NJ: Cortical activation and synchronization during sentence comprehension in highfunctioning autism: evidence of underconnectivity. Brain 2004;127:1811-1821.

93 Rippon G, Brock J, Brown C, Boucher J: Disordered connectivity in the autistic brain: challenges for the 'new psychophysiology'. Int J Psychophysiol 2007;63:164-172. 